GENETICS AND INTERRELATIONSHIPS OF FRUIT AND SEED SIZE IN Arachis hypogaea L.

BY

IGNACIO J. DE GODOY

A DISSERTATION PRESENTED TO THE GRADUATE COUNCIL

OF THE UNIVERSITY OF FLORIDA IN

PARTIAL FULFILLMENT OF THE REQUIREMENTS

FOR THE DEGREE OF DOCTOR OF PHILOSOPHY

UNIVERSITY OF FLORIDA 
To my parents, Ignacio and Isabel, with my deepest respect and admiration. 


\section{ACKNOWLEDGEMENTS}

I wish to express my sincere appreciation to Dr. A.J. Norden, advisor and chairman of my supervisory committee, for his advice and encouragment throughout my work at the University of Florida; to Drs. G.E. Bowes, W.G. Duncan, E.S. Horner and F.G. Martin for their assistance while serving as members of my supervisory committee; to Drs.D.D. Baltensperger and D.A. Knauft for kindly reviewing this dissertation; and to Dr. L.C. Monaco for his help and incentive in making my graduate studies possible.

I also wish to thank the Instituto Agronomico de Campinas (IAC) for providing me the opportunity for a superior education, to Empresa Brasileira de Pesquisas Agropecuarias (EMBRAPA) for granting my scholarship until March 1981; and to Conselho Nacional de Pesquisa (CNPq ) for the financial support provided from March to June 1981.

I am deeply thankful to my wife, Sonia, for her help and understanding, and for sharing with me every moment of this experience; to her, our children and our families for their continuous presence and support. 


\section{TABLE OF CONTENTS}

Page

ACKNOWLEDGEMENTS $\ldots \ldots \ldots \ldots \ldots \ldots \ldots \ldots \ldots \ldots \ldots \ldots \ldots \ldots \ldots \ldots \ldots$

LIST OF TABLES................................... v

LIST OF FIGURES.................................. vii

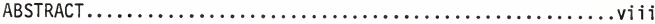

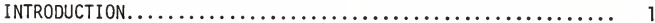

LITERATURE REVIEW................................. 3

Physiological Basis for Size Differences............. 3

Maternal Influence on Seed Size.................... 5

Peanut Fruit and Seed Development................... 9

Inheritance Studies............................... 10

Heritabilities.................................. 12

Correlations.................................... 14

MATERIALS AND METHODS $\ldots \ldots \ldots \ldots \ldots \ldots \ldots \ldots \ldots \ldots \ldots, 17$

RESULTS AND DISCUSSION.......................... 29

Frequency Distributions and Comparisons Between Means.. 29

Correlations................................. 42

Heritabilities.............................. 51

Seed Size with Reduced Pod Restraint................. 58

Growth of Individual Parental and $F_{1}$ Seeds........... 63

SUMMARY AND CONCLUSIONS.......................... 75

BIBLIOGRAPHY................................... 80

BIOGRAPHICAL SKETCH............................. 86 


\section{LIST OF TABLES}

Table

Page

1 Cross number and parents involved............. 17

2 Numbers of plants and/or seeds measured in each cross

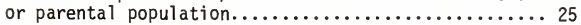

3 Observed and theoretical means and genetic estimates for mean seed weight (SWE) in four crosses......... 38

4 Observed and theoretical means and genetic estimates for mean shell weight (SHEWE) in four crosses....... 39

5 Estimates of genotypic correlation between all pairs of twelve variables for the $F_{2}$ population of Cross

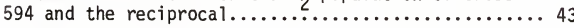

6 Estimates of genotypic correlations between all pairs of twelve variables for the $F_{2}$ population of Cross

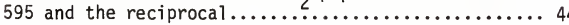

7 Estimates of genotypic correlations between all pairs of twelve variables for the $F_{2}$ population of Cross

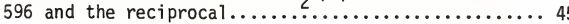

8 Estimates of genotypic correlation between all pairs of twelve variables for the $F_{2}$ population of Cross

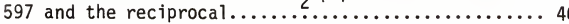

9 Estimates of genotypic correlations between all pairs of twelve variables for the $F_{3}$ population of Cross 594 and the reciprocal..........................

10 Estimates of genotypic correlation between all pairs of twelve variables for the $\mathrm{F}_{3}$ population of Cross 596 and the reciprocal ......................... 48

11 Narrow-sense heritabilities for thirteen variables estimated by regression of $F_{3}$ progeny means on individual $F_{2}$ plants in two peanut crosses......... 52

12 Broad-sense heritabilities for thirteen variables in the $F_{2}$ generation of four peanut crosses........53

13 Broad-sense heritabilities for thirteen variables in the $\mathrm{F}_{3}$ generation of two peanut crosses......... 54 
Table

14 Narrow-sense heritabilities for eight variables estimated by regression of $\mathrm{F}_{3}$ plant means on individual $\mathrm{F}_{2}$ fruits (or seeds) in two plant

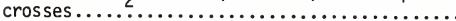

15 Mean and coefficient of variation (CV) for SWE and corresponding $\mathrm{ABOSW}$ in eight parental populations, and the percentage weight increase due to abortion...6 60

16 Mean and coefficient of variation (CV) for SWE and corresponding $A B O S W$ per generation for the cross and reciprocal cross populations and the percentage weight increase due to abortion.................... 61

17 Regression equations and coefficients of determination $(r 2)$ for dry seed volume and weight $(Y)$ against fruit age in weeks $(X)$ during the linear phase in parental and reciprocal hybrid seeds of Cross $596 \ldots \ldots \ldots \ldots .65$ 


\section{LIST OF FIGURES}

Figure

Page

1 Frequency distribution and mean seed and she 11 weight for the parents (Krinkle and Early Bunch) and $F_{2}$ progeny (Cross 594A and 594B)............ 30

2 Frequency distribution and mean seed and she 11 weight for the parents (Krinkle and 77-2115) and $F_{2}$ progeny (Cross 595A and 595B).............. 31

3 Frequency distribution and mean seed and shel1 weight for the parents (Krinkle and Jenkins Jumbo) and $F_{2}$ progeny (Cross 596A and 596B)............ 32

4 Frequency distribution and mean seed and shell weight for the progeny (77-1765 and 77-2115) and $\mathrm{F}_{2}$ progeny (Cross 597A and 597B).............. 33

5 Frequency distribution and mean seed and shell weight for the parens (Krinkle and Early Bunch) and $F_{3}$

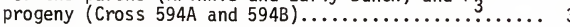

6 Frequency distribution and mean seed and shell weight for the parents (Krinkle and Jenkins Jumbo) and $F_{3}$

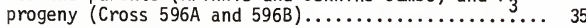

7 Dry seed volume increase with age in weeks of parental and hybrid seeds in Cross $596 \ldots \ldots \ldots \ldots \ldots \ldots \ldots . \ldots 64$

8 Fresh seed volume increase with age of selfed Krinkle and hybrid seeds in Cross 596A................. 68

9 Fresh fruit volume increase with age of Krinkle fruits bearing selfed and hybrid seeds in Cross 596A. 69

10 Fresh seed volume increase with age of selfed Jenkins Jumbo and hybrid seeds in Cross 596B....... 70

11 Fresh fruit volume increase with age of Jenkins Jumbo fruits bearing selfed and hybrid seeds in

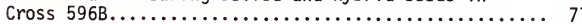




\begin{abstract}
Dissertation Presented to the Graduate Council of the University of Florida in Partial Fulfillment of the Requirements for the Degree of Doctor of Philosophy
\end{abstract}

\title{
GENETICS AND INTERRELATIONSHIPS OF FRUIT AND SEED SIZE IN Arachis hypogaea L.
}

\author{
By
}

\author{
Ignacio J. de Godoy \\ August 1981
}

Chairman: A.J. Norden

Major Department: Agronomy

Growth and final size of individual fruits and seeds were studied in crosses involving peanut Arachis hypogaea L. genotypes differing largely in these characteristics. The objective was to examine the genetics and interrelationships between fruit and seed size on the bas is of their differential segregation.

Parental, $F_{1}, F_{2}$ and $F_{3}$ populations were evaluated in four crosses. The degree of dominance and the minimum number of genes were assessed for seed and shell weight. Genotypic correlations, and broad and narrow-sense heritability estimates were calculated. The size of seeds grown with reduced pod restraint was studied by observing the weight of seeds from pods in which one of the seeds had aborted. Growth of parental and hybrid $F_{1}$ seeds was studied by observing weekly the fresh and dry volume increases.

The crosses of genotypes with large differences in fruit and seed size produced significant skewness of the offspring means toward the smaller parent, suggesting dominance. However, the degree of dominance was not as pronounced when the offspring means were compared with the geometric means of the parents. Thus, the size traits may actually be 
additively inherited, and behaving in a geometric fashion, probably as a result of genes controlling growth rates.

Frequency distributions of seed and shell weight were similar and correlations between fruit and seed size were positive and significant. Furthermore, the growth patterns of reciprocal $F_{1}$ hybrid seeds were not identical, each reciprocal tending to resemble its selfed counterpart indicating the strong role of the maternal environment on the expression of size.

Growth curves of the large parent, Jenkins Jumbo, and of the corresponding reciprocal hybrids were dissimilar. Seeds growing with reduced pod restraint appeared to attain a genetically determined size. In addition, there was heritable variation among the segregates for fruit density and shelling percentage, suggesting that the seed's genotype also plays a role in its phenotypic size expression.

The high estimates of narrow-sense heritability for fruit and seed size ( $h^{2}=0.67$ to 0.83$)$ indicate that these traits can be effectively selected in early generations. The calculated minimum number of factors responsible for the expression of seed and shell weight ranged from 4 to 26 suggesting that these traits should be treated quantitatively. 
INTRODUCTION

The peanut (Arachis hypogaea L.) is a crop in which the yield potential has not been fully explored. Differences in rate and duration of growth of individual fruits and seeds may potentially be used to develop higher-yielding cultivars through breeding. In this respect, the final size attained by fruits and seeds may be directly involved, since size is the end result of growth rate and duration. A great deal of research has been carried out in crops such as corn (Zea mays L.), wheat (Triticum aestivum L.) and soybeans (Glycine max L. Merr.), but in peanuts, only a limited amount of information is available, especially in segregating populations.

The fact that peanut seeds grow within a rigid maternal envelope (pod) may pose complications in breeding for size. As in other legumes, the cotyledonary and embryonic tissues of peanut seeds are one generation ahead of the seed coat (testa) and the pericarp (shell), which are maternal tissue. Thus, it can be hypothesized that there may be a differential segregation between maternal and embryonic tissue. If so, the size of the pericarp cavity may be considered a factor that can mask the genetics of seed size, particularly if there is heterozygosity. Seed growth could be either limited or rupture the shell when occurring inside pods having genetically smaller space than required by the seed.

knowledge of the mode of inheritance of fruit and seed size is necessary for increasing efficiency in breeding. However, previous studies on the genetics of either fruit or seed size in peanuts have not 
provided consistent information. Since, in most cases, the studies were made in breeding populations whose main features were not the variations in size "per se", it can be suggested that some of the characteristics involving segregation of fruit or seed size or other traits associated with size may have been hidden by the lack of sufficient distinctive features among the segregates. If so, a study of fruit and seed size made on segregating populations derived from crosses between widely divergent types would be likely to enhance the understanding of the fruit and seed size traits and their inter-relationships.

The objective of this research was to examine the genetics and interrelationships between fruit and seed size on the basis of their differential segregation, through the study of parameters of growth and final size of fruits and seeds in crosses involving peanut genotypes largely different in these traits. 


\section{LITERATURE REVIEW}

\section{Physiological Basis for Size Differences}

It is known that the rate of accumulation of dry matter into the seeds and the duration of this process are major determinants in seed yield. Assuming that fruit and seed size reflect the potential upper limits of these factors, then size has an impact on yield, thus contributing to the capacity of the sink apparatus.

There are indications that either growth rate or duration can be the factor determining differences between genotypes. Schenk (1961) found that the difference in final size between small Spanish and large Virginia peanuts was a result of a difference in duration of growth rather than in growth rate. However, Williams and Allison (1978) reported that the differences in size were associated with differences in growth rate among the four peanut cultivars they studied.

Individual kernel growth rates in corn ranged from $6-10 \mathrm{mg} / \mathrm{day}$ among cultivars and were correlated to some degree with final kernel weight (Carter and Poneleit, 1973). In wheat, variation in grain weight has been attributed to differences in the duration of grain filling (Asana and Bagga, 1966; Syme, 1967) or to variation in the rate of grain growth (Asana and Williams, 1965; Bingham, 1967; Brocklehurst, 1977) or to a combination of both (Stamp and Geisler, 1976).

Differences in growth rate of individual seeds among soybean cultivars were associated with differences in seed size, although the differences found in yield were not correlated (Egli, 1975; Egli 
et al., 1978). Differences found in seed size between two common-bean cultivars were attributed to differences in individual seed growth rates, since they had similar durations of pod filling (Hsu, 1979).

The physiological basis for genotypic differences in rate and duration of growth and consequently of size can be explained at a cellular level. Almost all of the differences in size and general form of an organ, as well as of the organism, arise from differences in number, activity and persistence of the centers of cell division (Milthorpe and Moorby, 1974).

MacArthur and Butler (1938) investigated the origin of size differences among tomato (Lycopersicum sp.) fruits. Fruit size within a genotype was dictated by the size of the cells and among genotypes, by the number of cells. Number of cells was determined by different rates of cell division during the pre-anthesis period and size of the cells was determined by the time, post-anthesis, allowed for the cells to expand.

In wheat, the evolutionary increase in grain weight did not involve an increase in size of the endosperm cells (Dunstone and Evans, 1974). Final grain weight in two cultivars of wheat was mainly dependent on the rate of accumulation of dry matter, which in turn was related to the number of endosperm cells formed within 14 days after anthes is (Brocklehurst, 1977).

Davies (1975) reported that the final dry weight of individual pea (Pisum sativum L.) seeds was related to both number and dry weight of cotyledon cells. The same author (Davies, 1977) reported highly significant correlations in 12 Vicia species between seed weight and cotyledon cell number and between weight and mean cell mass, most of the 
variation in seed weight being attributed to variation in the size of the cell population and only a small fraction being due to differences in cell mass.

\section{Maternal Influence on Seed Size}

In legumes, the cotyledons form the vast majority of the seed mass. Since they are part of the embryo, they are one generation ahead of the plant that bears them. However, this cellular apparatus depends on the photosynthetic supply translocated from the plant. This raises the question as to what is the causal genetic ability to translocate assimilates to the seeds. Also, if both causes affect seed size, the contribution of each should be known.

Davies (1975) studied seed size in reciprocal crosses of pisum sativum L. varieties and observed similarities in weight between the hybrid seeds and the seeds resulting from their selfed counterparts. However, since certain crosses showed $F_{1}$ seeds larger than their respective parental seeds, it was suggested that seed size was controlled by two systems: an intrinsic one dependent on the seed's own genotype and the extrinsic control provided by the maternal environment.

In soybeans, seed growth rate and stage of seed development were found to be closely related, suggesting that seed growth rate is primarily controlled by regulatory mechanisms within the seed, rather than by external availability of assimilates (Koller, 1971). This suggestion was confirmed through observations that only a limited effect on the rate of seed growth is obtained by altering the source-sink ratio (Egli and Leggett, 1976). In addition, seed growth rates were not found to 
differ between early and late pods. This constancy also emphasizes the role of the seed genotype (Egli et al., 1978). However, it has been also suggested that, since the seed is dependent on the rest of the plant, the supply of photosynthate would provide an overriding control on the rate of seed growth (Egli and Leggett, 1976).

Hedley and Ambrose (1980), studying pea seed development, recognized phases of high growth rates separated by phases of less active growth (lag phases). A similarity among genotypes for the time when these events occurred was reported, which appeared to relate to the time from anthesis and not to any particular physiological state. This suggested that seed development in peas appears to be determined by the maternal parent. However, the amount of growth occurring during these timed developmental phases would probably be dependent on relationships within the seed itself.

A number of reports involving chemical composition of the seeds provide variable information as to the presence of plant-embryo genotype interactions. In soybeans, the seed's own genotype has little influence in protein percentage (Singh and Hadley, 1972). 0 il content is determined by the maternal parent (Brim et al., 1968; Singh and Hadley, 1968) although small but significant paternal effects were found in $F_{1}$ seeds (Singh and Hadley, 1968). No indication was found that sugar content depends on the seed's genotype (Openshaw and Hadley, 1978).

In common beans (Phaseolus vulgaris L.), the control of protein percentage (Porter, 1972) and oil percentage (Leleji et al., 1972) is largely maternal. The same is reported for protein content in sunflower (Helianthus annuus L.) (Pawlowski, 1964) and rapeseed (Brassica napus L.) (Grami and Stefansson, 1977). A slight effect of the seed genotype on oil content of rapeseed was reported (Grami and Stefansson, 1977) 
and some amount of embryo control on certain fatty acids was observed (Thomas and Kondra, 1973).

In corn, control of protein content is largely maternal (Garwood and Lambert, 1967). 0il content $c$ an be influenced by the embryo genotype (Gilbert, 1961; Garwood et al., 1970). In sunflower seeds, either quality or quantity of oil is apparently controlled by the seed's own genotype (Yermanos et al., 1967).

In addition to the plant's ability to translocate these assimilates to the seed and the plant's ability to accept assimilates there may be other factors affecting seed growth: the pod envelop itself and the interaction resulting from the apparent independence existing between pod and seed growth.

Some reports indicate that growth of legume seeds lags behind the growth of the pods, so that by the time the pod walls attain the ir maximum weight, seed weight is still increasing linearly. Furthermore, there is some evidence indicating that this differential growth pattern varies according to the genotype. Fresh weight of seeds of the cultivar 'Wye' lagged behind pod dry weight by approximately 14 days (Quebedeaux and Chollet, 1975). Pods of 'Cutler' soybeans reached their maximum dry weight by the time the seeds had accumulated $15-30 \%$ of the ir final weight (Egli, 1975). Dry weights of "Amsoy-71" and "Norman" pods reached their maximum values around 20 days before those of the seeds, that is, at mid-pod filling (Thorne, 1979). In 6 lines of peas observed, this period ranged from 10 to 20 days (Hedley and Ambrose, 1980). 
In peanuts, Schenk (1961) reported that pods of 'Dixie Spanish' peanuts reached their maximum dry weight around the 17 th day after the pegs had penetrated the soil while seed dry weight reached its maximum value around the 42 nd day. Dry weight of 'Virginia Bunch-67' pods plateaued after 21 days while seeds reached their maximum dry weight only after 75 days.

This independence between pod and seed growth may help identify another factor influencing seed size: the mechanical barrier offered by the pod when the seeds have a genotype for growing larger than the volumetric capacity of the pod.

Since little attention has been given to this type of pod/seed interaction, very little is known about the consequences of this relationship of the potential genetic size and, thus, on the potential sink capacity of legume plants.

It was demonstrated that growth of soybean pods can be mechanically restricted and that such restriction will cause the seeds to ripen earlier and to be smaller (Duncan et al., 1979). In two soybean crosses, the $F_{1}$ (cross-fertilized) seeds could not be distinguished from the self-fertilized seeds on the basis of differences in size, when a large-seeded type was used as the pollen parent (Kilen, 1980).

In peanuts, the tightly packed seeds with in Spanish pods suggest that seed growth is abruptly arrested due to back pressure built up in the seeds as the growth is restricted by the surrounding shell (Schenk, 1961). When crosses were made between peanut lines differing in pod and seed size, differences in reciprocal $F_{1}$ seeds were observed. Hybrid seeds growing inside the small parental pods tended to be similar in 
size to the small parental seeds (Godoy and Norden, 1981). It has been also suggested as evidence that in two-seeded pods, when one seed fails to develop, the other can grow larger, sometimes filling the whole pod cavity (Duncan et al., 1979).

\section{Peanut Fruit and Seed Development}

Among the legumes, peanuts have a unique feature in that the pods develop underground. After fertilization, an intercalarly meristem at the base of the ovary becomes active, causing the formation of the gynophore, which elongates with the ovary at its tip (Smith, 1950). Ovary development only takes place after the gynophore penetrates the soit. Practically no ovary enlargement occurs in the light (Schenk, 1961; Ziv and Zamski, 1975).

Schenk (1961) described the various stages in the development of Virginia and Spanish pods. Virginia pods reached full size 3 weeks after the pegs had penetrated the soil, but the period of development for the small Spanish pods was one week shorter. As mentioned before, in both cases, seeds lagged behind pod development. In the Virginia pods, the inner parenchymatous tissues of the shell collapsed as the seeds expanded to fill the shell cavity. The same occurred with Spanish pods except that in these, the cavity was filled earlier and therefore the maturation seemed considerably shorter and more abrupt.

The packing of the Spanish seeds (Schenk, 1961) can reflect the inability of the seeds to grow further, as mentioned before. One reason is that the morphological structure of the shell does not appear to allow any sort of enlargement or splitting of the pods caused by the force of seed expansion. The mature peanut pod (pericarp) is composed 
of 3 layers of tissue: the two outer layers (exocarp and mesocarp) are composed of sclerified parenchyma (Gregory et al., 1951; Halliburton et al., 1975) confering to the pod a greater rigidity as compared to other legumes .

\section{Inheritance Studies}

The literature concerning inheritance of fruit and seed size has shown variable information. Divergent conclusions, especially those related with the type of gene action, may well have been originated from the type of data upon which the analyses were based. This may lead to misinterpretation and failure in reaching the goals set at the beginning of a breeding program.

Hammons (1973) reviewed the early literature on pod size inheritance. Early reports indicated dominance of large pods, size being reported as either multigenic or governed by only three genes.

Inheritance of seed size has also been studied. Hayes (1933) divided seed length in the $F_{2}$ into three classes and failed to produce a good fit. However, when seeds were considered in only two groups, long and short, a 15:1 ratio was observed, indicating a two factor difference with long dominant. Hull (1937) could easily classify seeds of $\mathrm{F}_{2}$ and $\mathrm{F}_{3} \mathrm{plants}$ into three classes: short, intermediate and long. He reported that the intermediate group was so truly intermediate that dominance of either shape could not be detected.

From crosses involving small-podded Spanish lines with largepodded mutants, Patil (1972) obtained $F_{1}$ plants with large pods, similar to one of the parents, suggesting dominant gene action for large size. However, the frequency distribution in the $F_{3}$ population showed 
$60 \%$ of the plants as having size similar to that of the small parent. Seed size behanved similarly to pod size in both $F_{1}$ and $F_{\underline{3}} 3$. It ws suggested that the low frequency of large sizes in $F_{3}$, despite the dominance expressed in $F_{1}$, reflected the influence of "modifying factors" in the expression of large size.

In a cross between two lines, one having $33.7 \mathrm{~g} / 100$ seeds and the other having $94 \mathrm{~g} / 100$ seeds, no dominance was found in segregating generations. It was calculated that five pairs of genes control seed size, four of them having isodirectional effects (Martin, 1967).

Mohammed et al. (1978) studied variability in the $F_{2}$ and $F_{3}$ generations from crosses involving Virginia and Spanish lines, and obtained significant non-additive effects for pod length and seed weight.

The studies of $F_{1}$ and $F_{2}$ generations in diallel crossings have also revealed differences regarding gene action. The majority of the Fl's in Wynne et al. (1970) crosses showed fruit length and seed weight means above the midparents. Additive gene action was suggested, since general combining ability gave higher estimates than the specific combining ability. Gibori et al. (1978) reported that in most crosses small pods were dominant, generally showing the $F_{2}$ mean below the midparent. It was suggested that the large pod size $(3 \mathrm{~g} / \mathrm{pod})$ would be homozygous recessive or nearly so. Cahaner et al. (1979) observed that, in some crosses, mean pod weight did not deviate from the midparent in either $F_{1}$ or $F_{2}$ generations. In others, $F_{1}$ and $F_{2}$ means were similarly smaller than the midparent. Yet, in other crosses, $F_{1}$ 's had means greater than the respective midparent, but $F_{2}$ 's were smaller. 
In long beans (Vigna sesquipedalis Fruw.), partial dominance for short pod and light seed has been observed (Mak and Yap, 1980). Similar observation was made for seed weight in an interspecific cross of soybeans when non-transformed data were used (Weber, 1950). However, from a diallel cross of common beans, Dickson (1967) found that pod length was under additive genetic control without dominance. Bassett and Woods (1978) studied pod lengths in a cross between two common bean cultivars and observed that the $F_{1}$ mean was a little larger than the midparent. However, the $F_{2}$ mean was skewed toward the small parent.

In safflower (Carthamus tinctorius L.) crosses, Kotecha and Zimmerman (1978) reported that domesticated species tended to have larger seeds and that large seed weight was partially dominant. In wheat, it has been reported that kernel weight is essentially governed by additive gene action. However, partial (Bhatt, 1972; Sun et al., 1972) to complete (Millet and Pinthus, 1980) dominance toward the larger size has also been observed.

\section{Heritabilities}

Although pod and seed size have been generally considered to be qualitatively inherited (Hammons, 1973), they have been treated as yield components, along with other pod and seed characteristics such as shelling percentage and maturity. As such, the heritability $\left(h^{2}\right)$ of these traits is often obtained as one of the breeding parameters. Heritability estimates for pod and seed size, along with other yield components, have been shown to vary a great deal. The population studied and the method applied in the estimation are factors that can influence the conclusions. 
Dixit et al. (1970), working with several homozygous lines, reported estimates of broad sense heritability of 0.87 and 0.88 for mean pod and seed weight, respectively. Shelling percentage and number of mature pods per plant had values of 0.72 and 0.78 , respectively. When 57 cultivars were studied in 3 environments (Dixit et al., 1971), the average values of 0.29 to 0.54 were obtained for dry weight of mature pods per plant. When 40 cultivars were studied during 2 years and broad sense heritabilities were estimated, values of 0.95 for mean pod weight and 0.86 for mean seed weight were obtained. Heritabilities for shelling percentage and number of days to maturity were also high $\left(\mathrm{h}^{2}\right.$ values of 0.86 and 0.99 , respectively). The number of mature pods per plant had an estimate of 0.58 .

In addition to the fact that broad sense heritability tends to inflate the estimate because it considers the total genetic variance (Falconer, 1976), estimates of heritability using a population of homozygous lines will probably lead to additional overestimation. Thus, the use of crosses between diverse lines is advisable (Hammons, 1973).

The use of $F_{2}$ and backcross data yielded an estimate of narrow sense heritability for mean peanut seed weight of 0.66 while the broadsense heritability was 0.76 (Martin, 1967). The use of offspring-parent regression gave an estimate of narrow sense heritability of 0.41 and broad sense heritability of 0.43 for mean seed weight, in a population derived from a cross between small and large-seeded peanut lines (Patil, 1972).

In Patil's (1972) cross, broad sense heritability for shelling percentage was 0.44. Sandhu and Khehra (1977) obtained broad sense estimates ranging from 0.48 to 0.62 , while narrow sense estimates ranged from 0.04 to 0.36 when using the backcross method. 
Coffelt and Hammons (1974) reported broad sense heritabilities around 0.80 for peanut pod (width and length) and 0.90 for mean seed weight. The number of pods per plant gave broad sense estimates around 0.40, similar to values obtained by Patil (1972).

Wynne and Rawlings (1978) studied the variability of yield traits from a cross between two Virginia peanut cultivars up to the $F_{6}$ generation. The narrow sense heritability estimated through the analys is of variance components showed values of 0.89 for fruit length and 0.62 for number of sound mature kernels.

A comparison between methods of calculating narrow sense heritability can be made from the study of Mohammed et al. (1978) involving two crosses between Spanish and Virginia lines. In both crosses, and for all traits measured, estimates from the offspring-parent regression procedure were much lower than those from the variance analys is. For fruit size, estimates by regression ranged 0.18-0.50 and by variance they ranged from 0.73 to 0.92 .

The use of offspring-parent regression appears to be accepted for its reliability, since it generally yields more conservative values (Bassett and Woods, 1978).

\section{Correlations}

Correlation estimates are frequently used in breeding programs. They are useful in the process of selection since they can reveal the degree of interdependence between traits. In peanuts, relationships of pods and seeds with each other and with other related characteristics have been reported. Ramanathan and Raman (1968) found shelling percentage significantly and positively correlated wt in mean pod weight $(r=0.403$ to 0.811$)$ and mean seed weight $(r=0.318$ to 0.836$)$. 
However, in a population of homozygous lines (Kushwaha and Tawar, 1973), shelling percentage was negatively correlated with mean pod weight $(r=-0.427)$ and with mean seed weight $(r=-0.392)$, these last being significantly and positively correlated between themselves $(r=0.427)$. The number of mature pods was not significantly correlated with mean seed weight, but it was positively correlated with mean fruit weight $(r=0.413)$ at the $5 \%$ level.

Significant and positive phenotypic correlations between pod size and mean seed weight was reported by Patil (1972) in $F_{3}$ populations of crosses involving small Spanish and large-podded mutants ( $r=0.765$ and 0.787). Pod size and shelling percentage were significantly and negatively correlated $(r=-0.319$ and -0.357$)$.

In the $F_{2}$ 's from crosses between Spanish and Runner lines (Coffelt and Hammons, 1974) the phenotypic correlations between mean seed weight and pod size (length and width) were also significant and positive $(r=0.65$ to 0.75$)$. The number of pods per plant was essentially uncorrelated with mean seed weight $(r=-0.06$ to -0.14$)$ and with pod length or width $(r=-0.04$ to -0.22$)$, although some of the $r$ values were significantly negative at the $1 \%$ level.

In $F_{2}$ and $F_{3}$ populations of crosses between Spanish and Virginia types (Mohammed et al., 1978) the genotypic correlations between fruit size (fruit length and mean fruit weight) and shelling percentage ranged from $r=-0.20$ to $+0.45^{\star \star}$. Fruit size and the percentage of mature fruits were generally uncorrelated except for one of the crosses in a particular location, when values were negative and ranged from $r=-0.13$ to $-0.41 \star \star$. 
Significant phenotypic correlations between seed and fruit volume obtained from $F_{2}$ populations ranged from $r=+0.83$ to +0.98 but larger fruits tended to be less dense than small fruits since correlations between size traits and fruit density ranged from $r=-0.36^{\star \star}$ to $-0.83^{\star *}$ (Godoy and Norden, 1981). In this study, shelling percentage was generally uncorrelated with fruit or seed size. 


\section{MATERIALS AND METHODS}

Five peanut genotypes having distinct sizes of fruits and seeds were utilized in four different crosses and their reciprocals (Table 1). The table also shows the identification number of the reciprocal cross by which it is referred from now on.

Table 1. Cross number and parents involved.

\begin{tabular}{ll} 
Cross Number & \multicolumn{1}{c}{ Parents } \\
\hline 594 A & Krinkle $\times$ Early Bunch \\
594 B (Reciprocal) & Early Bunch $\times$ Krinkle \\
595 A & Krinkle $\times 77-2115$ \\
595 B (Reciprocal) & $77-2115 \times$ Krinkle \\
596 A & Krinkle $\times$ Jenkins Jumbo \\
596 B (Reciprocal) & Jenkins Jumbo $\times$ Krinkle \\
597 A & $77-1765 \times 77-2115$ \\
597 B (Reciprocal & $77-2115 \times 77-1765$ \\
\hline
\end{tabular}

The lines were chosen and crossed in such a way so as to obtain distinct parental combinations, the principal feature of each cross 
being the difference between parents regarding fruit and seed size. Some of the characteristics related to each genotype can be described as follows:

Krinkle--A crinkled-leaf mutant from a Spanish line, whose leaf characteristic is a dominant genetic marker (Hammons, 1964). The seeds are very small (30 g/100 seed) and uniform, these being the reasons this genotype was used in three of the crosses.

Early Bunch--A spreading bunch growth habit cultivar. Seeds are large, of the Virginia market-type, 100 seeds weighing around $105 \mathrm{~g}$. The cultivar is characterized as having uniform and well filled pods (Norden et al., 1977).

77-2115--A runner growth habit experimental line (UF 77-2115) with pods approximately similar in size to those of Early Bunch. However, the seeds are a little smaller, $100 \mathrm{~g}$ per 100 seeds. Jenkins Jumbo--A runner growth habit variety characterized by very large pods and seeds (Hammons and Norden, 1979). Pods are we 11 filled and 100 seeds weigh above $140 \mathrm{~g}$.

77-1765--A Spanish experimental genotype (UF 77-1765) with small pods and seeds. Pods are well filled and the weight of 100 seeds is $35 \mathrm{~g}$. This line produces an appreciable number of split pods. Crosses were made during the spring of 1979 in the greenhouse at the University of Florida Agronomy Farm. The $F_{1}$ plants were grown in a spaced-plant nursery during the winter 1979-80 in Puerto Rico. 
An average of 20 dried, two-loculed pods, judged fully mature by their external appearance (hardness and pronounced roughness of the external surface) were sampled from each $F_{1}$ plant. Weight and volume of each pod were recorded and volume determinations were made by recording the volume of water displaced after immersing the pod in a graduated cyl inder.

After every volume determination, the pod was placed in an open dish on absorbent paper under an air current to remove the humidity due to the immersion in water. Pods were then opened and the weight and volume of the apical and the basal seed were recorded following the same procedure described above. By basal seed it is meant the mature embryo that developed closest to the attachment of the pod to the gynophore, the apical seed being the more distant.

Volume determinations have proved to be a reliable procedure for size measurements in seeds of safflower (Pawlowski, 1963), peanuts (Godoy and Norden, 1981), common beans (Hsu, 1979) and peas (Hedley and Ambrose, 1980). It is obvious that it could hardly be used as a routine practice such as genotype screening or selection. However, it is a simple and efficient method when it is important to detect small size differences (especially in materials that have irregular shapes) and when density is to be calculated as the ratio mass/volume.

The $F_{2}$ seeds, as well as seeds from each parent, were fungicide-treated and planted in the field on June 15, 1979, at the University of Florida Green Acres Agronomy Farm, Gainesville, in Arredondo fine sand. The seeds were sown $60 \mathrm{~cm}$ apart with $91 \mathrm{~cm}$ between rows. This spacing was chosen so as to reduce interplant competition. Cultural practices were performed following guidelines used commercially for peanuts in Florida. 
Self-pollinated $F_{2}$ fruits containing $F_{3}$ seeds were obtained at harvest, as well as the fruits from the self-pollinated parents. Fruits were obtained only from those plants which appeared healthy and developed normally throughout the season. The time of harvest was based on previously described indicators of physiological maturation, such as: general yellowing of foliage, loss of older leaves, hardness and pronounced roughness of the external pod surface (Sturke and Buchanan, 1973) and decrease in peg strength (Bailey and Bear, 1973).

Since these methods are said to show only partial reliability for identifying fully mature segregates, especially in a crop such as peanuts in which the fruits develop underground, an additional measure was adopted and that was to establish harvesting dates between or similar to the harvesting dates of the parents.

The durations of the cycles of the parental lines from planting to harvesting for the 1979 growing season were as follows: Krinkle--117 days; Early Bunch--126 days; 77-2115--133 days; Jenkins Jumbo--146 days; 77-1765--110 days.

After drying, pods were handpicked and a random sample of 10 apparently mature pods was taken from each plant and kept separate from the remaining fruits from then on. An additional way to help insure that the samples consisted only of fully mature pods was provided by taking those pods closest to the tap root. In addition, although certain plants exhibited some one and three-loculed fruits, only the two-loculed fruits were considered throughout the experiment. 
Weight and volume of fruits $\left(F_{2}\right)$ and seeds $\left(F_{3}\right)$ were obtained from each ten-fruit sample as a whole, except for those plants that were randomly selected to generate the $F_{3}$ lines. In these, weight and volume of the individual pods (before and after shelling), and of the basal and apical seeds were recorded as previously described for the $F_{j}$ 's.

A pedigree system of notation was used throughout the experiment so that the plants and the individual pods and seeds measured could be identified and traced back to their original parentage.

Additional characteristics of fruitification in each $F_{2}$ and parental plant were obtained as follows: 1) total number of pods per plant; 2) percentage of mature pods (by external evaluation, as previously described); 3) percentage of split pods; 4) percentage of pods with aborted seeds; and 5) weight of the remaining seeds found in item 4.

By "split pods" it is meant any two-loculed pod that presented some degree of separation along the pod suture before being subjected to any mechanical pressure after harvesting.

"Pods with aborted seeds" were considered those fully developed two-loculed pods which contained a single seed, the other seed being confined to a trace of embryonic tissue or being completely absent. A sample of twenty pods was evaluated in each plant to produce the percentage indicated. A few cases in which both seeds presented abnormal development were not characterized as abortion. It was assumed that embryo failure occurring after the ovaries have started developing (characterizing the so called "pop" condition) is likely to be due to inherent characteristics of the plant rather than to nutritional defficiency (Smith, 1956). 
For the $F_{3}$ generation, two of the four original crosses were used. Cross 594 and 596 were chosen because they showed significant contrasts between crosses and because the parents involved are widely known varieties.

The individually measured $F_{3}$ seeds as well as seeds from each parent were fungicide-treated and planted in the field on May 7, 1980, at the University of Florida Green Acres Agronomy Farm, Gainesville, in Arredondo fine sand. Planting space and cultural practices were similar to those used for the $F_{2}$ plants in the previous year. Care was taken to maintain identity not only of the progeny lines, but also of the individual plants with in lines, since they were previously identified by the pedigree of the individual seeds planted.

The criteria used for determination of the maturity date for individual $F_{3}$ plants were the same as those used for the $F_{2}$ 's. The durations of the cycles of the parental lines from planting to harvesting for the 1980 growing season were as follows: Krinkle--114 days (1); Early Bunch--125 days (3); and Jenkins Jumbo--144 days (5). The numbers in parentheses were assigned to each parent so as to rate the line by lateness or earliness of maturity. For the 594, 595 and 597 crosses, segregates were assigned maturity ratings of 1,2 or 3 . For the cross 596 ratings were $1,2,3,4$ and 5 since there is an approximate difference of as much as 30 days between maturity dates of Krinkle and Jenk ins Jumbo.

Self-pollinated $F_{3}$ fruits containing the $F_{4}$ seeds were obtained at harvest, as well as the fruits from the self-pollinated parents. The criteria used for harvesting and sampling were similar to those used for the $F_{2}$ plants. Samples of 10 pods were used for the weight and volume determinations of pod and seeds. 
Additional characteristics of each $F_{3}$ and parental genotype were recorded as follows: 1) vegetative growth habit; 2) percentage of mature pods; 3) percentage of split pods; 4) percentage of pods with aborted seeds; 5) weight of the remaining seeds found in item 4 .

Vegetative growth habit is the rating from 1 to 9 of the angular position of the cotyledonary branches in 75-day- old plants. A rating of 1 to 3 identifies the erect type (more characteristic of the Spanish type of growth) while 7 to 9 identifies the spreading (runner) type, with branches developing close to the soil surface (Norden, personal communication).

From all the weight and volume measurements, four other variables could be obtained, as follows: fruit density = fruit weight/fruit volume; seed density = seed weight/seed volume; shell weight $=$ fruit weight $-2 x$ seed weight $)$; and shelling percentage $=(2 \times$ seed weight)/fruit weight.

Table 2 shows the sizes of cross and parental populations in each generation according to weight and volume measurements obtained on a per plant or per seed basis.

To facilitate presentation, the variables referred to herein will be expressed by the following initials:

FWE average fruit weight, in $\mathrm{g}$

FVO average fruit volume, in $\mathrm{ml}$

SWE average seed weight, in $\mathrm{g}$

Svo average seed volume, in $\mathrm{ml}$

FDEN average fruit density, in $\mathrm{g} / \mathrm{ml}$

SDEN average seed density, in $\mathrm{g} / \mathrm{ml}$

SHEWE average shell weight, in $\mathrm{g}$

SHEPCT shelling percentage 
MAT percentage of mature pods

SPT percentage of split pods

ABOPCT percentage of pods with aborted seeds

ABOSW average weight of seeds in pods with aborted seeds

HARV maturity date ratings

TOPD total number of pods

VEG vegetative growth habit ratings

The number of observations obtained for each of the variables is shown in Table 2. Since not all the plants presented aborted seeds, the variable ABOSW had fewer observations, as indicated by the numbers in parentheses.

Frequency distributions were drawn for each parental and segregating population for the variables seed and shell weight, each point corresponding to the percentage of individuals in the corresponding weight class. Among the fruit and seed variables recorded throughout the experiment, shell and seed weight were used because average dry weight is the most widely used estimator of size and is thus more suitable for comparisons with other studies.

Since the $F_{1}$ 's were measured by individual fruit and seeds in contrast to the measurements made on ten-fruit samples of the $F_{2}$ 's and $\mathrm{F}_{3}$ 's, corrections were necessary so that the means could be compared. The corrections were made in the $F_{1}$ means in each cross by calculating the percentage increase of the arithmetic mean between parents measured on an individual fruit basis in relation to that measured on a ten-fruit basis. This percentage was subtracted from the $F_{1}$ mean to obtain the corrected value.

The estimations presented in Table 3 and 4 were obtained as follows: 
Table 2. Numbers of plants and/or seeds measured in each cross or parental population

\begin{tabular}{|c|c|c|c|}
\hline \multirow[t]{2}{*}{ Generation } & \multirow{2}{*}{$\begin{array}{c}\text { Cross or } \\
\text { Parent }\end{array}$} & \multicolumn{2}{|c|}{ Population Size } \\
\hline & & Plants & Seeds \\
\hline \multirow[t]{8}{*}{$F_{1}$} & $594 \mathrm{~A}$ & - & 96 \\
\hline & $594 B$ & - & 98 \\
\hline & $595 \mathrm{~A}$ & - & 94 \\
\hline & $595 B$ & - & 92 \\
\hline & $596 \mathrm{~A}$ & - & 82 \\
\hline & $596 \mathrm{~B}$ & - & 94 \\
\hline & $597 \mathrm{~A}$ & - & 68 \\
\hline & $597 \mathrm{~B}$ & - & 66 \\
\hline \multirow[t]{8}{*}{$F_{2}$} & $594 A$ & $82(31)$ & 228 \\
\hline & $594 B$ & $108(39)$ & 216 \\
\hline & $595 \mathrm{~A}$ & $44(20)$ & 172 \\
\hline & $595 B$ & $47(22)$ & 176 \\
\hline & $596 \mathrm{~A}$ & $63(32)$ & 222 \\
\hline & $596 B$ & $63(29)$ & 210 \\
\hline & $597 \mathrm{~A}$ & $43(29)$ & 184 \\
\hline & 5978 & $60(36)$ & 178 \\
\hline \multirow[t]{5}{*}{ Parents } & Krinkle & $46(4)$ & 98 \\
\hline & Early Bunch & $38(10)$ & 98 \\
\hline & $77-2115$ & $35(17)$ & 84 \\
\hline & Jenkins Jumbo & $49(11)$ & 96 \\
\hline & $77-1765$ & $28(7)$ & 98 \\
\hline \multirow[t]{4}{*}{$\mathrm{F}_{3}$} & $594 \mathrm{~A}$ & $184(91)$ & - \\
\hline & $594 \mathrm{~B}$ & $181(91)$ & - \\
\hline & $596 \mathrm{~A}$ & $163(85)$ & - \\
\hline & $596 B$ & $166(110)$ & - \\
\hline \multirow[t]{3}{*}{ Parents } & Krinkle & $35(7)$ & - \\
\hline & Early Bunch & $30(18)$ & - \\
\hline & Jenkins Jumbo & $26(17)$ & - \\
\hline
\end{tabular}




$$
\begin{aligned}
& M P=\text { arithmetic mean between the parents }=\left(\bar{P}_{1}+\bar{P}_{2}\right) / 2 \\
& G M=\text { geometric mean between the parents }=\sqrt{\bar{P}_{1} \times \bar{P}_{2}} \\
& \left(h_{1}\right)=\text { degree of dominance }=\left(\bar{F}_{1}-M P\right) /\left(\bar{P}_{1}-M P\right) \text { (Petr and } \\
& \quad \text { Frey, 1966). } \\
& \left(h_{2}\right)=\text { degree of dominance }=\left(\bar{F}_{1}-G M\right) /\left(\bar{P}_{1}-G M\right) \\
& \text { Inbreeding depression\% }\left(\bar{F}_{1}-\bar{F}_{2}\right)=100\left(\bar{F}_{1}-\bar{F}_{2}\right) / \bar{F}_{1} \\
& \quad \text { (Singh, 1973) } \\
& \text { Inbreeding depression\% }\left(\bar{F}_{1}-\bar{F}_{3}\right)=100\left(\bar{F}_{1}-\bar{F}_{3}\right) / \bar{F}_{1}
\end{aligned}
$$

where

$$
\begin{aligned}
& \bar{P}_{1}=\text { mean of the small parent } \\
& \bar{P}_{2}=\text { mean of the large parent } \\
& \bar{F}_{1}, F_{2} \text { and } \bar{F}_{3}=\text { means of the } F_{1}, F_{2} \text { and } F_{3}
\end{aligned}
$$

populations, respectively.

For the above calculations, the means for Krinkle, Early Bunch and Jenkins Jumbo represent the average of two years.

The "min imum number of factors" $(K)$ was calculated by $\frac{\left(\bar{P}_{1}-\bar{P}_{2}\right)^{2}}{8 \times V_{G}}$, where $V_{G}$ is the genotypic variance as described for the broad-sense heritability estimates. The $K$ estimate depends on the assumptions that the genes act additively, and that the loci have equal effects and are not linked (Falconer, 1976).

The narrow sense heritabilities represent the slope of the regression of the $F_{3}$ progeny means on the means of the $F_{2}$ plants (Falconer, 1976). The broad-sense heritabilities were calculated within crosses and within generations, as:

$$
h^{2}=\frac{V_{F_{2}}-\sqrt{V_{P_{1}} \times V_{P_{2}}}}{V_{F_{2}}} \text { (Mahmud and Kramer, 1951), }
$$


Weber and Moorthy, 1952; Coffelt and Hammons, 1974; Mohammed et a1., 1978). The pooled parental within plot variance (variance among indivicual parental plants in two years) is represented by the expression $\sqrt{V_{P_{1}} \times V_{P_{2}}}$. This value is subtracted from the $F_{2}$ (or other generation) within plot variance to estimate the genotypic variance, the denominator of the equation being the phentoypic variance. The validity of the equation depends on the assumptions that environmental factors affect both segregating and parental genotypes to the same extent and that the variability observed within the parental lines is solely environmental, since the lines are homozygous.

The genotypic correlations were calculated as described by Petr and Frey (1966):

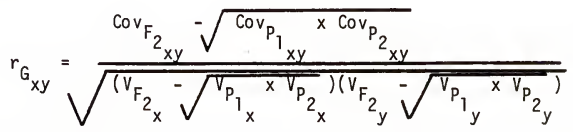

where $\operatorname{Cov}$ and $V$ represent covariance and variance, respectively. The expressions in parentheses in the denominator represent the genotypic variances for traits $x$ and $y$, calculated as mentioned before. The Cov values are the phenotypic covariances contained in the equation for estimating the phenotypic correlations between $x$ and $y$ with each segregating population, i.e.,

$$
r_{p_{x y}}=\frac{\operatorname{Cov}_{x y}}{\sqrt{v_{x} \times v_{y}}}
$$

The significance tests were performed by comparing the estimates with table values of $r$ at the 95 and $99 \%$ levels of significance (Steel and Torrie, 1960). The degrees of freedom were considered n-2. Except for the variable $A B O S W$, all the others used the number of observations (plants) indicated in Table 2. The number of observations for ABOSW are shown in Table 3. 
Another experiment was carried out in the greenhouse at the Agronomy Farm, University of Florida, during the Spring of 1980. Crosses were made involving Krinkle and Jenkins Jumbo parents and the cross products as well as the products of the self-pollinated flowers were harvested at weekly intervals to determine the growth pattern of the hybrid seeds (growing within both maternal environments) in comparison to the growth of the self-pollinated seeds. The cross 594 (Krinkle $x$ Jenkins Jumbo) was chosen since it represents the greatest range of sizes existing in this material.

Krinkle flowers were pollinated with pollen from Jenkins Jumbo and vice-versa, while other flowers in the same parental plants were allowed to self-pollinate. The crossing and the system of identification of the pegs were made following the techniques described by Norden (1973). Pegs were marked with colored wires soon before soil penetration and the date of pegging was recorded. In order to avoid any difference in fruit development due to differences in date of pegging, a table was used in which each peg was identified by a number and the harvesting was done by fruit age across dates of pegging. At each harvesting date the fresh volume of individual unopened healthy fruits was recorded. Fruits were then opened and the fresh volume of both seeds per pod was taken. Seeds were kept separate and their volume was again recorded after drying at $60^{\circ} \mathrm{C}$ for 48 hours. Growth of fruits and seeds was plotted against time in weeks (Figures 7 to 11). An average of 5 observations was obtained for each data point.

In order to compare the growth of parental and hybrid seeds with emphasis on the linear phases, the dry volume data were separated into three phases (Dure, 1975), the linear phase in each curve being tentatively obtained through estimations of linear regression equations. 


\section{RESULTS AND DISCUSSION}

\section{Frequency Distributions and Comparisons Between Means}

Figures 1 to 6 show the frequency distributions and means of seed and shell weights of parental and segregating populations from four different crosses. Differences between reciprocals, as well as comparisons of the mean of each cross with the midparent (MP) and the geometric mean (GM) were studied. In each cross, reciprocals were considered separately so as to detect differences that might reflect the presence of extra-nuclear factors (Figures 1 to 6 ). If maternal inheritance were present, reciprocals $A$ and $B$ would each resemble more its maternal parent. However, in all crosses studied, the reciprocal means and the distributions were not different enough to indicate cytoplasmic influence on shells or seeds, both reciprocals behaving similarly as to their locations along the range between the parents.

The most noticeable feature observed was the tendency of the mean of both reciprocals to be closer to the small parental mean than to the large parental mean. Although there were some small differences between seed and shell weight means within crosses, the tendency was essentially similar in both traits, i.e., almost all cross means deviated to some degree from the midparent value (arithmetic mean between the parents), falling somewhere between this and the mean of the small parent.

It can be also observed that the cross means tended to deviate further from the midparent in wider crosses such as that between Krinkle and Jenkins Jumbo. This would immediately suggest the presence of 


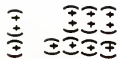

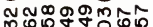
ن்0ல்-0் " " | " | | " "

$1 \times 1 \times 1 \times|x| x \mid x \frac{0}{\Sigma} \sum_{0}$

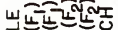

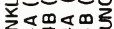

过守守

ชั
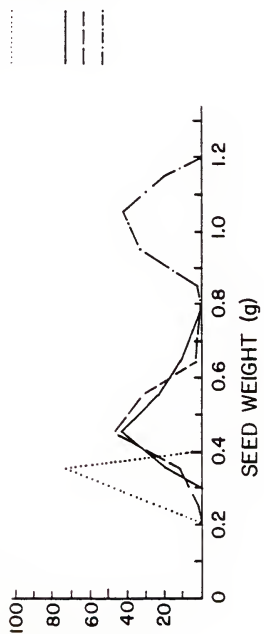

(\%)人ON $3 \cap 0 \exists y$
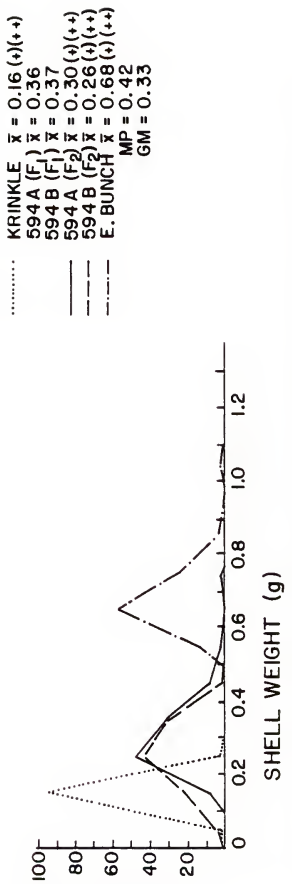

(\%) ᄉON $3 \cap 03 y$
过

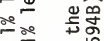

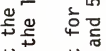

卌芒近

○

ขิ ญ

든 $\geq$ ก

$>\stackrel{\Xi}{>}$ ㅇํㅇ

廿.

प्रे 한

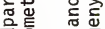

응 등

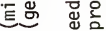

동 n $N$

ह 다

튼튼 这

받 不

ขํํㄴ든

षे

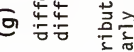

$\rightarrow \lambda$ t它

華苋 宁

ठु ठु

पष डे

'E

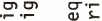

这

$\sim \sim$

듀 -

$\sum \frac{0}{2}$

$\Sigma$ 要

モき 要 


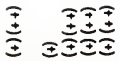

NmR

ตักเ์

0000000

" " " " | | " "

$|x| x|x| x|x| x Q=\sum_{0}$

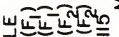

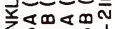

ㄴำ

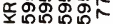

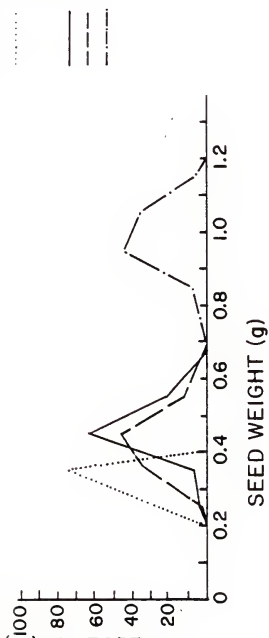

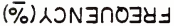
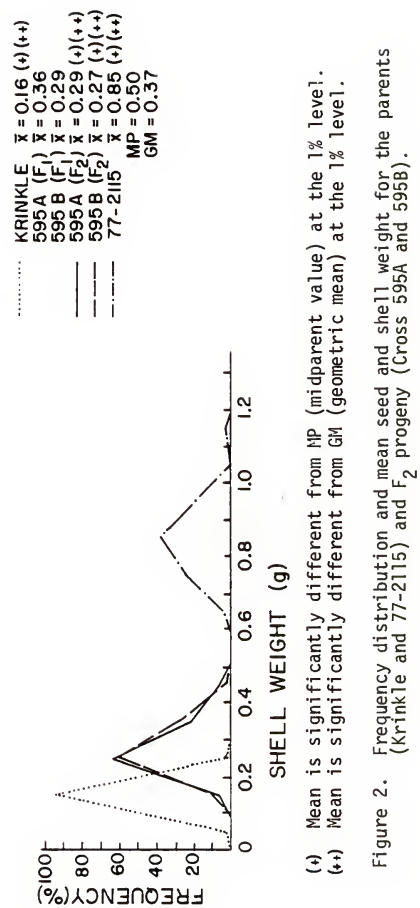


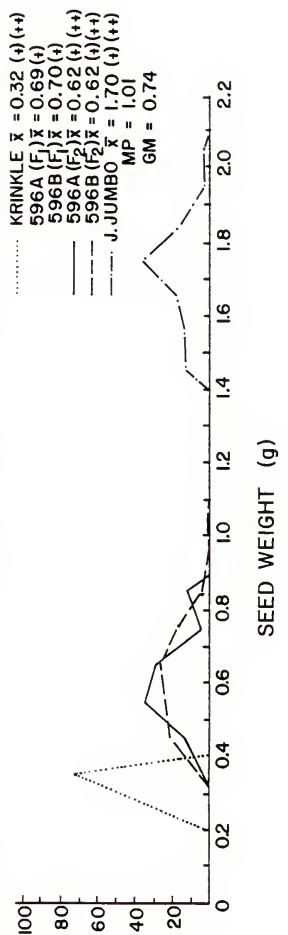

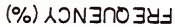

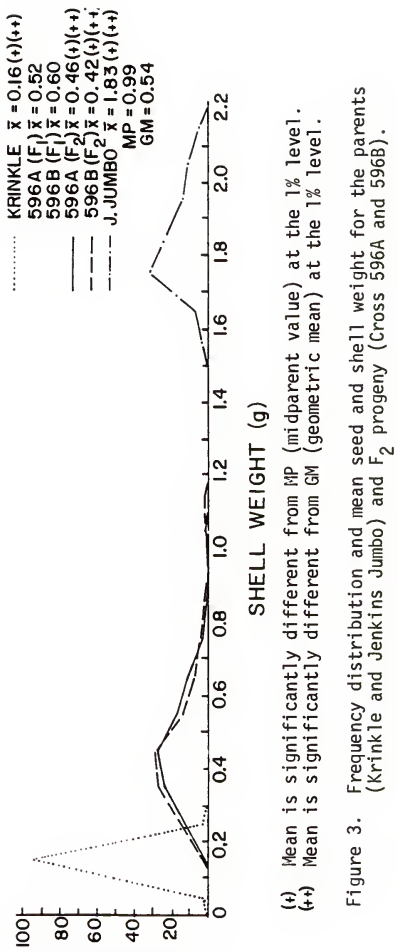

(\%) ᄉON $3 \cap 0 \exists y \exists$ 

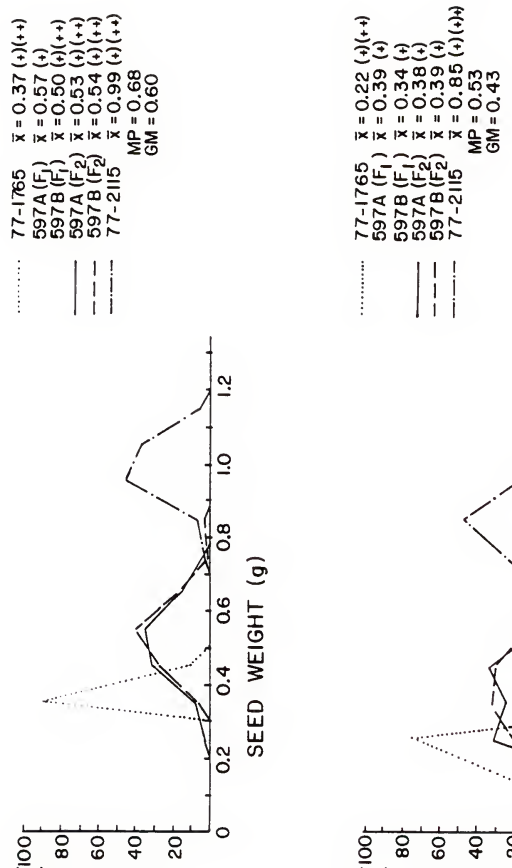

(\%)人JNヨกOت4y

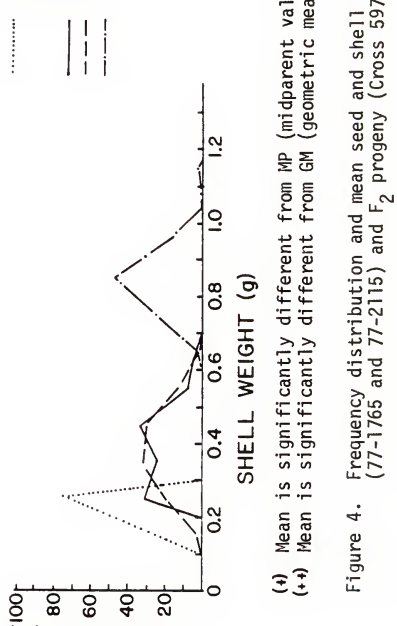

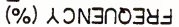

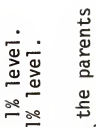

ㅎำ

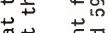

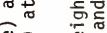

बิ

$>$ Е

๕U ज थ

它捳

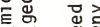

$=$ ज णू

E ฮู

แN

유

흥

존

in

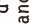

نे

ฮ

定

不

$55 \dot{0}$

$\frac{\omega}{2} \stackrel{\frac{1}{2}}{\frac{1}{3}}$ 


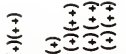

ब

○ं

|x|x|x|x|x|x 至至

U

느는

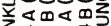

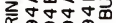

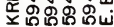

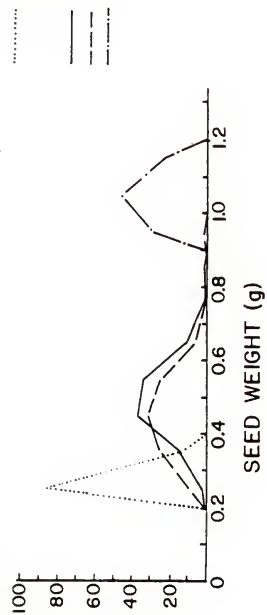

(\%) ᄉDN $3 \cap 0 \exists y]$
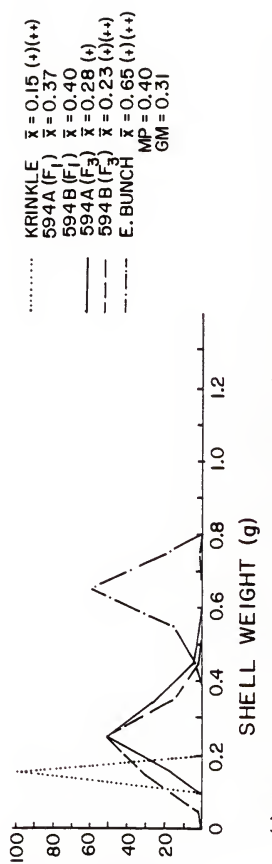

एक

i

一 웜

จำ फू

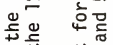

+

๙

ญ ह

๙ัฐ

+U $\quad \frac{d}{n}$

닌 몬

ชั

음 통 뮹

턴 岕

몰 눙

픙 틍 五 믕

ㄴㄴㄴ 릉드

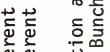

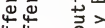

$44 \quad \frac{1}{2}$

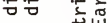

$\lambda \rightarrow$ in

늠

近 $\frac{0}{2}$

空关

온

는

$\simeq \approx$

드 10

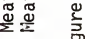

\pm \pm if

(\%)人JN $3 \cap 0 \exists y=$ 


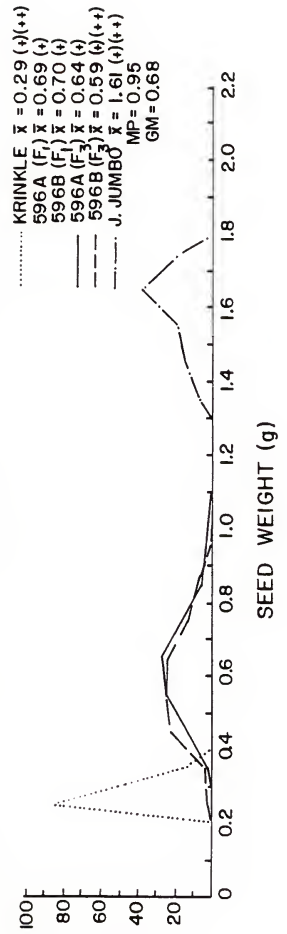

(\%) 人DN $\exists$ ก 34

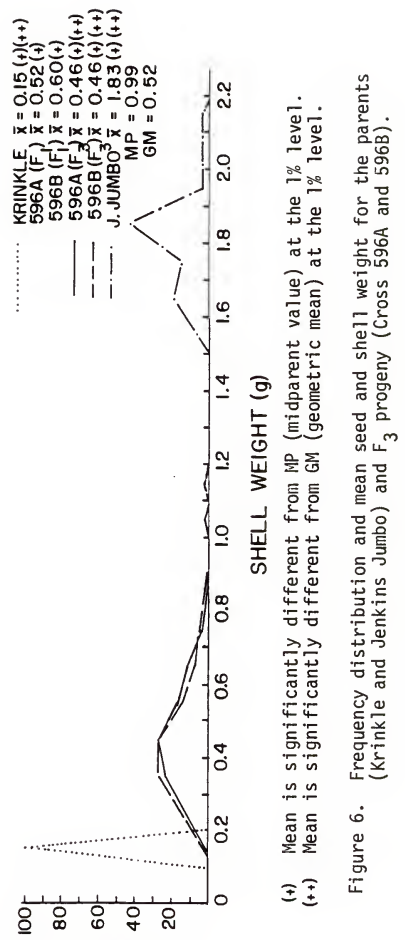

(\%)人DN 3 ก 
dominance of small size, Jenkins Jumbo probably having most size genes recessive. However, it is important to notice that the difference between the arithmetic and geometric means became larger as the difference between the parents increases. Furthermore, in those crosses where the distance between the parents was relatively small, the skewness of the distribution and the deviation of the mean from the midparent was less pronounced, the distance between the geometric and the arithmetic mean being also small.

The t-test analys is for comparison of the mean of each reciprocal cross population with MP and GM (Figures 1 to 6 ) indicated that the population means were significantly lower than the midparent (MP) in almost all cases. When compared to the geometric means (GM), greater similarities were observed especially between the geometric means and the $F_{1}$ means. Furthermore, in those crosses where the distance between the parents was relatively short, the skewness of the distribution and the deviation of the mean from the midparent was less pronounced, the distance beteen the geometric and the arithmetic mean being also short.

The facts mentioned above are in close agreement with an early hypothesis discussed in relation to the data on size of tomato fruits (MacArthur and Butler, 1938). The basic size factors would be those controlling rates of cell division or duration of active mitos is during ovary formation. Higher rates would produce ovaries with larger number of cells which, upon expansion would produce a fruit (or seed) with size proportional to that number. Since cell division causes the number of cells to increase geometrically, differences in size will also be geometric. Thus, if genes controlling rates of cell division act additively, a cross between large and small sizes would produce offspring 
with a mean size resembling the geometric mean and the distribution of individuals being more or less skewed toward the small size.

As mentioned earlier, small differences could be observed between seed and shell distributions in each cross. While, in Early Bunch the weight of one seed was greater than that of the shell, this difference was not as great in 77-2115 and, in Jenkins Jumbo, average seed weight was even lower than the average shell weight. However, the skewness of the distribution of the segregates relative to the parents followed the same rules mentioned before, i.e., the larger the parental difference, the more pronounced is the skewness toward the smaller parent. Despite these seed/shell differences, it is difficult to separate the segregation pattern of the seed from that of the shell since their behavior was essentially similar.

Tables 3 and 4 show the arithmetic and geometric means between the parents for each cross. These theoretical values can be compared with the actual means obtained in each cross and an estimate can be made as to the presence or absence of dominance.

Means from the crosses have been compared with the arithmetic means between parents, whether in single crosses (Petr and Frey, 1966; Kotecha and Zimmerman, 1978) or in diallel crosses (Cahaner et al., 1979; Wynne et al., 1970), the deviations being interpreted as dominance. From a work on an interspecific cross of soybeans, however, it was pointed out that for traits that involve growth rates, organ sizes, or similar volumetric characteristics, gene action cannot be defined until the proper scale of measurement is ascertained (Weber, 1950). 


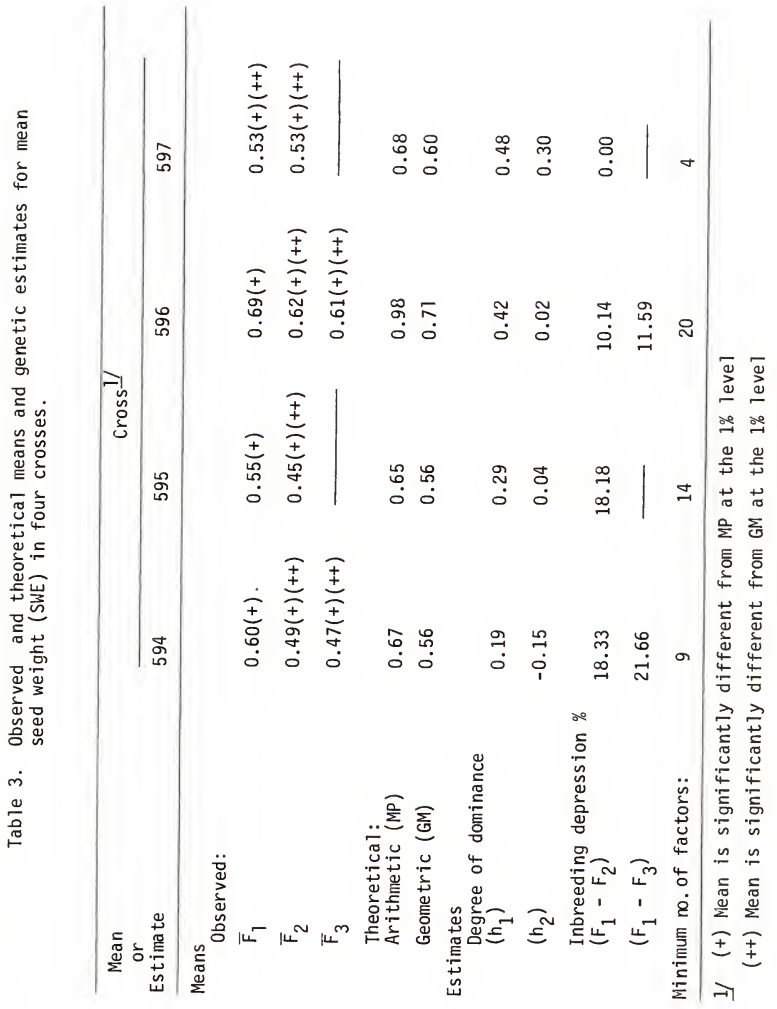




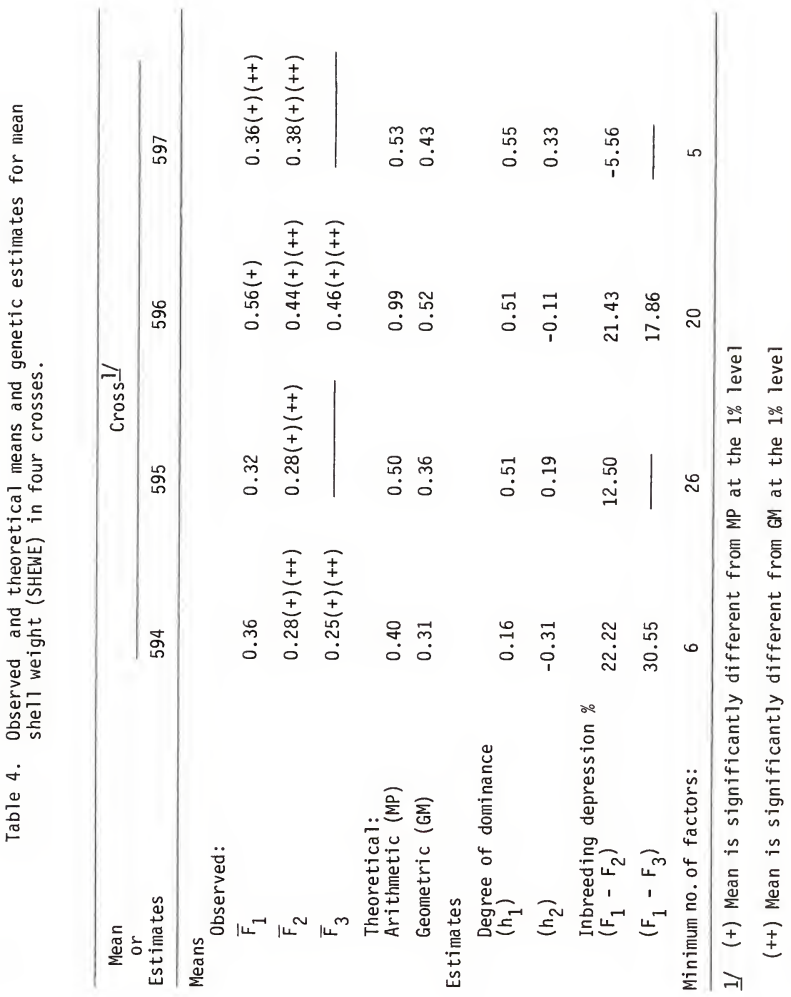


The t-test for significance between the $F_{1}$ means (both reciprocal combined) again showed a closer agreement with the geometric than with the arithmetic means of the parents, especially for shell weight. In crosses 594 and 595 both geometric and arithmetic means were not significantly different from the $F_{1}$ 's. The only exception was in Cross 597 where both $F_{1}$ 's were smaller.

The degree of dominance was used solely as a means to evaluate the differences obtained when this parameter was estimated by using MP or GM. From the results it can be noted that there are differences as to whether the degree of dominance was obtained by comparison with the arithmetic mean $\left(h_{1}\right)$ or with the geometric mean $\left(h_{2}\right)$. The $F_{1}$ means being closer to the geometric mean indicates a lower level of dominance when the data are considered on a geometric scale, since values for $\left(h_{2}\right)$ were smaller in magnitude than the $\left(h_{1}\right)$ values, except for shell weight in cross 594 .

While in Cross 595 and 596 the degree of dominance was greatly reduced from $\left(h_{1}\right)$ to $\left(h_{2}\right)$, Cross 597 showed an $\left(h_{2}\right)$ magnitude of 0.30 for seed weight. On the other hand, Cross 594 showed a change in the direction of the dominance when the geometric mean was used for the calculations.

From the observations above, it appears that, although there may be some dominance effect in certain crosses, the phenotypic expression of "dominance" for pod and seed size in peanuts is strongly conditioned by the difference between the parents and by the scale of measurement used. 
The offspring were concentrated closer to the small than to the large parent, especially in the wider crosses, indicating large genotypic differences between the parents involved. Thus, the use of distant lines as parents is not advisable if sizes similar to the large parent are desired.

In addition to the lower values of the $F_{1}$ 's in relation to the midparent value, a further depression of the means in the $F_{2}$ 's and $F_{3}$ 's was observed, to the point of making these means even lower than the geometric means. The calculated inbreeding depression percentages yielded positive values, except in cross 597. Positive values indicate that the depression occurred toward the smaller parent, i.e., farther from MP or GM. Weber (1950) observed similar behavior in an interspecific soybean cross and suggested either inbreeding or partial sterility as the cause for such phenomena. However, inbreeding depression cannot explain the results in such cases since the $F_{2}$ and $F_{3}$ means were lower than the $F_{1}$ and not higher, as it would be the case if dominance of the small size is assumed.

Since the present study involves widely divergent fruit and seed size types a certain amount of sterility could be suggested, which selectively favors the appearance of larger numbers of small-podded plants.

The calculations of the minimum number of factors by which the parental genotypes would differ in each cross agreed to some extent with the relative phenotypic difference between the parents. Although this estimate is not completely reliable since additivity, absence of linkage 
and equality of gene effects must be assumed, it provides some indication that several loci are involved in the inheritance of either seed or shell weight (or both).

\section{Correlations}

Tables 5 to 10 show the genotypic correlations estimated between size traits of fruits and seeds (namely, FVO, SWE, SVO and SHEWE) and other characteristics observed in populations derived from four crosses. Reciprocals were considered separately so that the estimates could be observed twice in each cross and each generation.

Size traits of fruits and seeds were highly and positively correlated among themselves. Thus, variation in size could be routinely evaluated by any of these measurements, probably by averaging pod weight, since it is the simplest and the most rapid procedure. However, despite these high estimates, the relationships involving traits such as FDEN and SHEPCT allow the detection of variations other than those inherent to size "per se": fruit density (FDEN) and shelling percentage (SHEPCT) yielded non-significant or significantly negative values when paired with the sizes traits (especially with FVO), the significant values being more frequently observed with FDEN than with SHEPCT. It may also be observed that correlations between either SVO or SWE with FDEN or SHEPCT were generally smaller in magnitude than the FVo vs. FDEN and FVO vs. SHEPCT pairs.

The observations discussed above indicate that, although seed size follows a pattern of segregation similar to that of pod size, therefore producing high correlation values between them, there still is variation in the ability of the seeds to fill pods completely, seeds being generally more tighly packed in the smaller pods. 


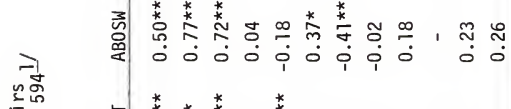

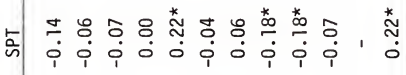

ฐ 死 동ํ

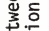

范

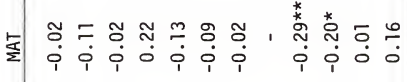

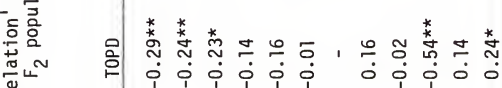

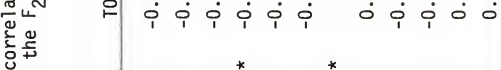

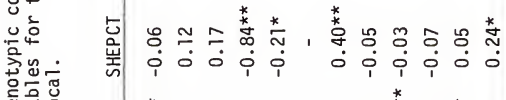
일. 융 का

4.5

\%

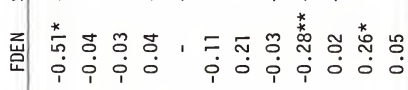

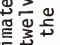
岀溇

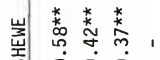

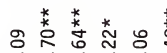

弯

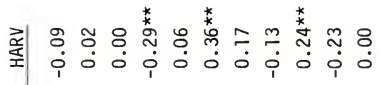

:




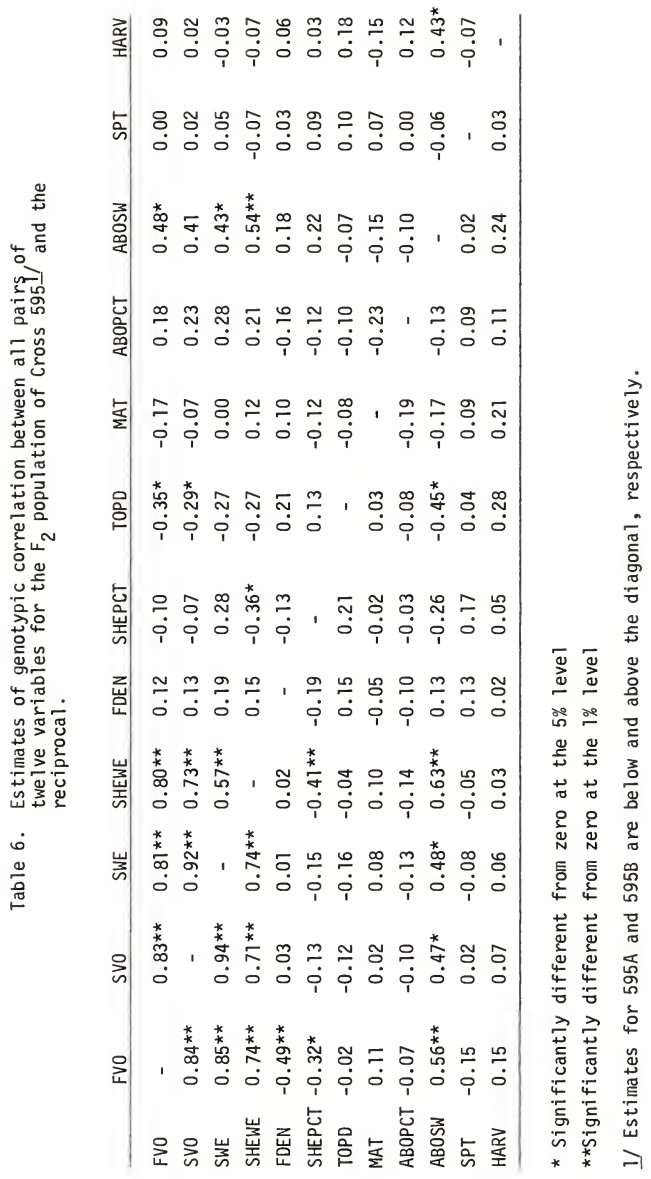




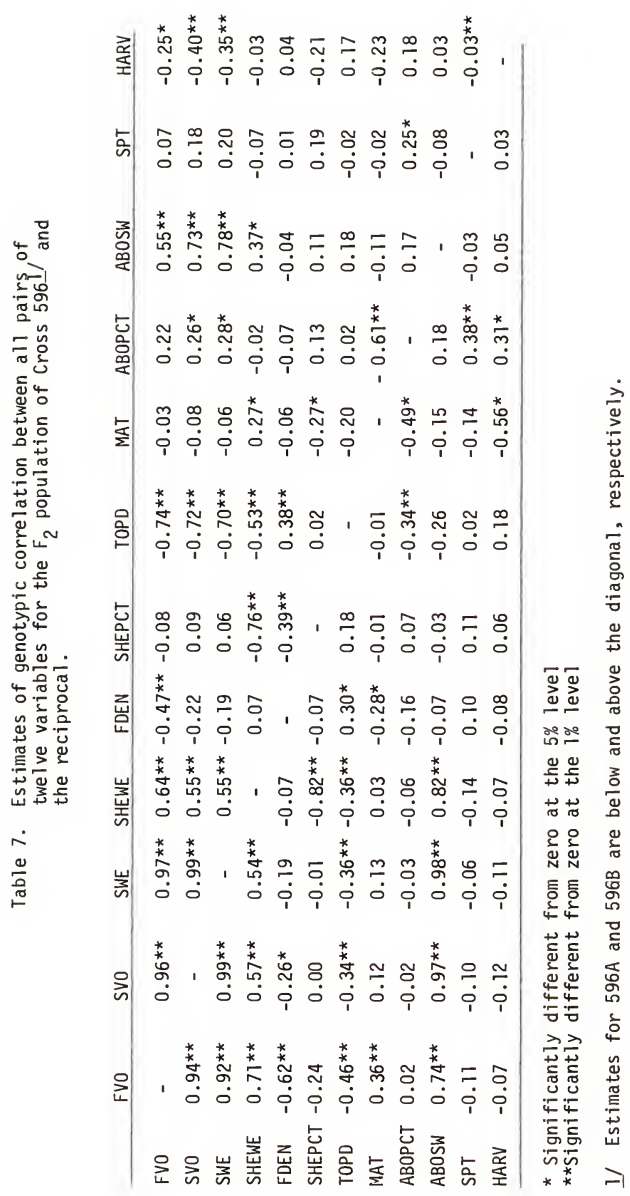




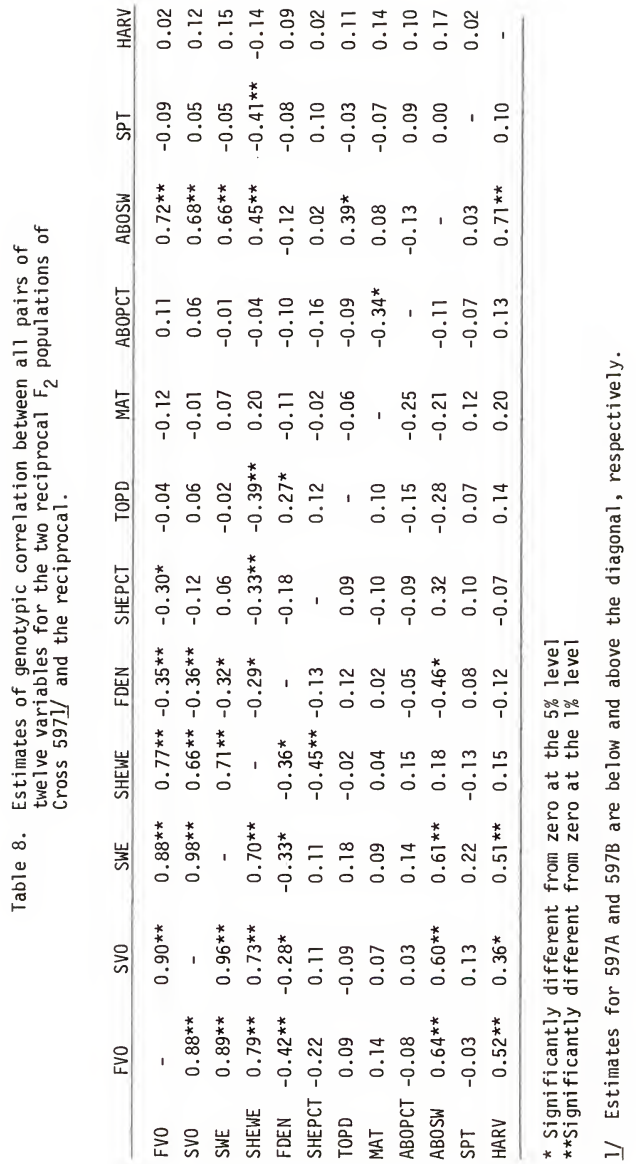




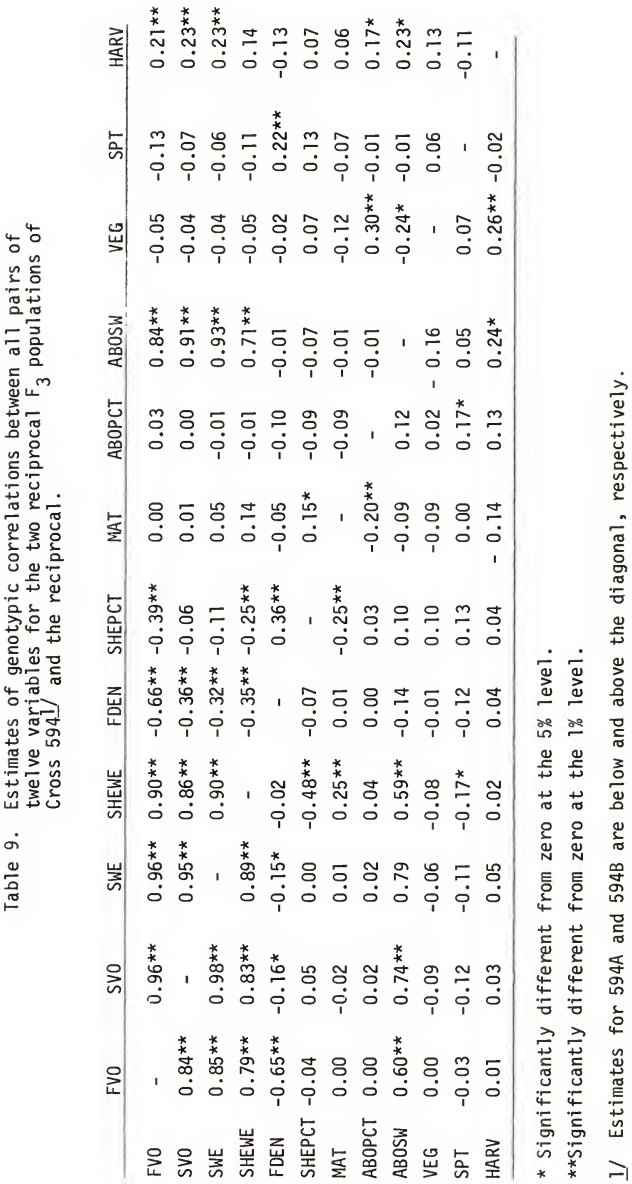




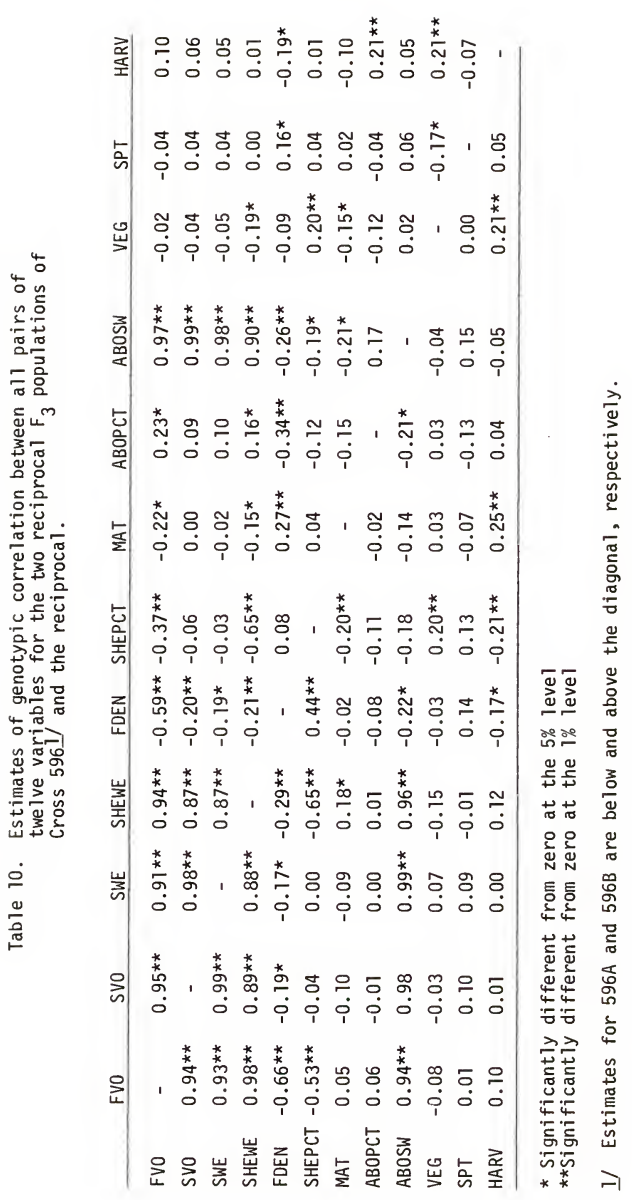


The total number of pods per plant was significantly and negatively correlated with size of fruits and seeds in the majority of the 8 $F_{2}$ populations observed. Estimates were particularly high in both populations of Cross 596. The lowest values observed were in Cross 597 where the estimates between TOPD and size traits were essentially nonsignificant. In the peanut literature size is not always correlated with number of pods (Soomro, 1975) although it tends to be neagtive (Coffelt and Hammons, 1974). The fact that, in the present case, the highest values were obtained in the widest of the crosses (596) suggests that substantial differences in size among the segregates should be necessary in order to produce detectable relationships between size and number of fruits or seeds.

The present crosses failed to show a strong relationship between size traits and the percentage of mature pods. Fruit density and she 1ling percentage also were not consistently related to MAT, indicating that the external appearance of mature pods is not always a good indicator of dense or well-filled pods.

Relationships between size traits and percentage of fruits with aborted seeds (ABOPCT) ranged from not significant to significantly positive, the strongest relationship being observed in the $F_{2}$ generation of Cross 594. This shows a slight tendency of larger-podded plants to present higher amounts of abortion. Higher abortion percentages also occurred in plants with higher proportions of immature pods. These relationships may suggest abortion as a mechanism by which peanut plants regulate their fruit load depending on the assimilate available. 
ABOSW was strongly correlated with the size traits, especially in the $F_{2}$ and $F_{3}$ generations of Cross 596, further indication of the maternal influence on the final seed size. However, it should be noticed that the magnitudes of the FVO vs. SWE correlations were higher than those of the FVO vs. ABOSW estimates. This observation, added to the fact that the estimates of FVO vs. ABOSW were higher in Cross 596, provides additional evidence that the maternal influence is not total, the genotype inherent to the seed itself playing a certain role in the final size reached by the seed.

SPT was not significantly correlated with size traits. In addition, the correlations between SPT and FDEN were generallly positive but non-significant, except in the $F_{2}$ population of Cross 594A. Thus, the appearance of split pods could not be explained on the bas is of growth of genetically larger seeds in small pod cavities.

Correlations involving maturity date (HARV) and size traits were too inconsistent to allow the identification of any relationship. Some consistency was observed in the positive estimates between HARV and the traits TOPD and VEG, although the values generally were not significant. Later-maturing $\mathrm{plants}$ tended to have greater numbers of fruits and more decumbent growth habits. In addition, VEG and HARV were, to a limited extent, positively correlated in both crosses studied.

Although small in magnitude, some significant estimates were obtained between HARV and ABOSW, no significant relationship being observed in populations of Cross 596 . 
Heritabilities

Table 11 shows estimates of narrow-sense heritability for thirteen variables in two crosses obtained from the the regression of the $F_{3}$ progeny means on the individual $F_{2}$ plants. Estimates from fruit and seed size, measured either by volume or weight, were high in both crosses, indicating that size traits can be effectively selected early in the breeding program.

Slightly smaller values for seed size in relation to those for fruit size can be observed. This indicates that seeds are more influenced by environmental variation than are the pods. The heritability of shell weight was lower, but it must be remembered, that shell weight values were obtained indirectly by subtracting SWE multiplied by two, from the FWE value which may have caused some additional nongenetic variation.

Fruit density and shelling percentage, both characteristics that indicate the extent to which the seeds filled the pods, showed medium values of heritability. Cross 596 producing values slighty higher. The broad-sense estimates (Tables 12 and 13) show that the genetic variation comprises over fifty percent of the total phenotypic variation. Seed density had a low heritability whether estimated in narrow or broad sense. Thus, most all the variation in seed density occurring between individual plants is likely to be environmental.

The percentage of mature fruits also shows a large proportion of environmental influence. The highest heritability estimate was 0.75 (broad sense) in the $F_{3}$ generation of Cross 594, but, in general, the values remained around 0.50 . Narrow-sense heritability was higher in 
Table 11. Narrow-sense heritabilities for thirteen variables estimated by regression of $F_{3}$ progeny means on individual $\mathrm{F}_{2}$ plants in two peanut crosses.

\begin{tabular}{lcc} 
Variable & \multicolumn{2}{c}{ Heritability } \\
\cline { 2 - 3 } & 594 & 596 \\
\hline FWE & 0.80 & 0.82 \\
FVO & 0.83 & 0.81 \\
SWE & 0.78 & 0.76 \\
SVO & 0.82 & 0.72 \\
FDEN & 0.29 & 0.47 \\
SDEN & 0.00 & 0.22 \\
SHEWE & 0.67 & 0.79 \\
SHEPCT & 0.37 & 0.39 \\
MAT & 0.48 & 0.10 \\
ABUPCT & 0.23 & 0.24 \\
ABOSW & 0.39 & 0.65 \\
SPT & 0.54 & 0.00 \\
HARV & 0.09 & 0.04
\end{tabular}


Table 12. Broad-sense heritabilities for thirteen variables in the $F_{2}$ generation of four peanut crosses.

\begin{tabular}{llccc}
\hline Variable & \multicolumn{4}{c}{$\begin{array}{c}\text { Heritability } \\
\text { Cross }\end{array}$} \\
\cline { 2 - 5 } & 594 & 595 & 596 & 597 \\
\hline FWE & 0.85 & 0.69 & 0.82 & 0.86 \\
FVO & 0.83 & 0.68 & 0.85 & 0.91 \\
SWE & 0.83 & 0.67 & 0.81 & 0.84 \\
SVO & 0.81 & 0.68 & 0.79 & 0.87 \\
FDEN & 0.60 & 0.54 & 0.67 & 0.44 \\
SDEN & 0.24 & 0.13 & 0.15 & 0.08 \\
SHEWE & 0.77 & 0.44 & 0.77 & 0.83 \\
SHEPCT & 0.69 & 0.40 & 0.77 & 0.83 \\
TOPD & 0.89 & 0.85 & 0.83 & 0.62 \\
MAT & 0.48 & 0.51 & 0.42 & 0.55 \\
ABOPCT & 0.74 & 0.88 & 0.86 & 0.82 \\
ABUSW & 0.60 & 0.00 & 0.23 & 0.05 \\
SPT $1 /$ & 0.90 & 0.94 & 0.80 & 0.70 \\
\hline
\end{tabular}

1/ Estimate in Cross 596 used $\left(V_{P_{1}}+V_{P_{2}}\right) / 2$ instead of $\sqrt{{P_{1}}_{1} \times V_{P_{2}}}$ as the pooled parental variance since the variance of SPT in Jenkins Jumbo was zero. 
Table 13. Broad-sense heritabilities for thirteen variables in the $\mathrm{F}_{3}$ generation of two crosses.

\begin{tabular}{lcc}
\hline Variable & \multicolumn{2}{c}{ Heritability } \\
\cline { 2 - 3 } & 594 & 596 \\
\hline Cross & 0.87 \\
FVD & 0.87 & 0.89 \\
SWE & 0.88 & 0.85 \\
SVO & 0.86 & 0.83 \\
FDEN & 0.86 & 0.72 \\
SDEN & 0.78 & 0.00 \\
SHEWE & 0.00 & 0.76 \\
SHEPCT & 0.66 & 0.66 \\
MAT & 0.42 & 0.42 \\
ABOPCT & 0.75 & 0.88 \\
ABOWSW & 0.90 & 0.50 \\
SPTI & 0.50 & 0.99 \\
VEG & 0.99 & 0.88 \\
& 0.59 & \\
\hline
\end{tabular}

1) Estimates in both crosses used $\left(V_{P_{1}}+V_{P_{2}}\right) / 2$ instead of $\sqrt{V_{P_{1}} \times V_{P_{2}}}$ as the pooled parental variance since the variances of SPT in Early Bunch and Jenkins Jumbo were zero. 
Cross 594 than in Cross 596. Since in cross 596 the narrow-sense estimate was much lower than the broad-sense estimate, it can be suggested that a component of the genetic variation other than the additive may be present to a higher degree when Krinkle is crossed with Jenkins Jumbo than when Krinkle is crossed with Early Bunch.

ABOPCT showed high values of broad-sense heritability, although the narrow-sense estimates were low. The equation for broad-sense heritability compares the phenotypic variance observed in the segregates in relation to that observed in the parents. Since the percentage of aborted seeds and the variation in this percentage were much lower in the parental lines, high values of broad-sense heritability were obtained. This indicates that the appearance of abortion in the crosses studied is due to genetic causes. The same could be applied to SPT, where the parental variation was very small or non-existent in some cases.

Values of heritability for ABOSW, whether narrow or broad-sense, were low or medium in magnitude. The values around 0.50 or over, especially the 0.65 narrow-sense heritability observed in Cross 596, confirm the hypothesis that seeds attain their size not only as a function of the sizes of the pod cavity, but also due to their own inherent genotypes, although one can expect as much as $50 \%$ of the variation to be attributed to the environment, when the seeds grow with less pod restraint.

Narrow-sense heritability was nearly zero for the maturity date ratings (HARV). However, the broad-sense estimates, if calculated, would be 1.00 in all cases because the variation within the parents was 0.00 , since all plants in each parent were harvested on the same day. 
It is likely that the procedure used here to identify canopy maturation is not reliable for use as a selection procedure, although it was useful to avoid leaving earlier-senescing plants in the field for longer periods of time.

The narrow-sense estimates for fruit and seed size were almost as large as the broad-sense values. In both generations of Crosses 594 and 596 the broad-sense values for fruit weight and volume ranged from 0.82 to 0.89 while estimates for seed weight and volume ranged from 0.79 to 0.86 . Both crosses considered, the narrow-sense values ranged from 0.80 to 0.83 for fruit weight and volume and from 0.72 to 0.82 for seed weight and volume. These observations characterize two points: 1) The larger values obtained for the narrow-sense regression estimates in relation to previous reports (Patil, 1972; Mohammed et al., 1978) are likely to be due to the broader range of sizes existing in crosses between widely different lines, such as in the present case; and 2) The lack of large differences obtained between the broad and narrow-sense estimates can be indicative of the strong role of the additive variance existing in these crosses.

Table 14 shows estimates of narrow-sense heritability obtained by regression of $F_{3}$ plant means on individual $F_{2}$ fruits (or seeds, when the traits are SWE, SVD or SDEN). The intention was to assess the possibility of breeding for size or pod-filling traits by using a single seed descent method, which would require less space and time in comparison with other methods. 
Table 14. Narrow-sense heritabilities for eight variables estimated by regression of $F_{3}$ $p l$ ant means on individual $F_{2}$ fruits (or seeds) in two peanut ${ }^{2}$ crosses.

\begin{tabular}{lll} 
Variable & \multicolumn{2}{c}{$\begin{array}{c}\text { Heritability } \\
\text { Cross }\end{array}$} \\
\cline { 2 - 3 } & 594 & 596 \\
\hline FWE & 0.63 & 0.58 \\
FVO & 0.60 & 0.48 \\
SWE & 0.53 & 0.46 \\
SVO & 0.44 & 0.46 \\
FDEN & 0.04 & 0.16 \\
SDEN & 0.02 & 0.04 \\
SHEWE & 0.48 & 0.43 \\
SHEPCT & 0.25 & 0.22 \\
\hline
\end{tabular}


By comparison with the estimates obtained in Table 11 a reduction was observed in the magnitude of heritability in all traits studied and in both crosses. This indicates that selection would not be as efficient using a single seed descent procedure as it woulb be when using average size per plant. It also indicates that a large portion of the withinplant variation in fruit and seed size and in the pod-filling attributes is non-genetic. On the other hand, it should be noted that, despite the non-genetic causes, there appears to be a significant portion of heritable variation since the heritability estimates were kept to a reasonably high level, especially for the fruit and seed size traits.

\section{Seed Size with Reduced Pod Restraint}

Few reports have documented seed abortion in peanuts, al though this is a commonly observed phenomenon. When a seed fails to develop during the peg stage, the portion of the ovary containing it also fails to grow. However, failures occurring after pod enlargement has begun do not seem to inhibit the completion of pod development, resulting in developed pods with generally a single seed (Smith, 1956).

Although calcium deficiency in the fruiting zone has been considered a major cause for embryo abortion, there is a certain percentage of seed failure even when calcium supply is adequate (Smith, 1954).

Taking advantage of this inherent loss of reproductive efficiency, an attempt was made to compare the average weight of seeds in two-seeded pods (SWE) with the weight of seeds found in those pods where one of the seeds had aborted (ABOSW). 
Tables 15 and 16 show the average SWE and ABOSW in the parental as well as in the segregating populations of four crosses, the average SWE, in this case, being calculated only from those plants that also produced data for ABOSW.

Since the causes and consequences of abortion cannot be completely defined, it is difficult to determine the degree of certainty with which the ABOSW means can represent the true potential size of the seeds, in quantitative terms. However, such values can provide additional information on the role of the maternal genotype on seed size and the importance of space limitation for seed growth. In addition, a certain quantification can be tried if the ABOSW values are considered as lower bounds of the growth capacity of individual seeds when compared to the SWE values.

Whether in the parental lines or in the segregates, ABOSW means were always larger than the corresponding SWE means. The coefficients of variation were also increased in all cases, especially in the parental populations, where they nearly doubled, indicating ABOSW presented larger susceptibility to environmental variations in relation to the SWE values where seeds do not grow so freely.

The fact that, when one seed aborts the other can grow larger, has been suggested as evidence for the mechanical limitation of seed growth (Duncan et al., 1979). This would also suggest that the filling period could be extended by providing the seeds with additional space so that their full development could be attained.

Some interesting observations can also be made if one compares the percentage increase in weight due to seed abortion in relation to the weight of seeds growing in pods with no abortion (Tables 15 and 16). 
Table 15. Mean and coefficient of variation (CV) for SWE and corresponding ABOSW in eight parental populations, and the percentage weight increase due to abortion.

\begin{tabular}{|c|c|c|c|c|c|}
\hline Population $1 /$ & $\begin{array}{l}\text { Mean } \\
\text { SWE }\end{array}$ & $\mathrm{CV}$ & $\begin{array}{r}\text { Mean } \\
\text { ABOSW }\end{array}$ & CV & $\begin{array}{c}\% \\
\text { Weight } \\
\text { Increase }\end{array}$ \\
\hline Krinkle (1979) & 0.32 & 4.06 & $0.39 \star$ & 12.05 & 21.87 \\
\hline Krinkle (1980) & 0.30 & 5.33 & $0.36^{\star \star}$ & 13.33 & 20.00 \\
\hline Early Bunch (1979) & 1.03 & 6.21 & 1.10 & 10.91 & 6.80 \\
\hline Early Bunch (1980) & 1.05 & 6.66 & $1.18^{\star \star}$ & 12.71 & 12.38 \\
\hline Jenkins Jumbo (1979) & 1.69 & 5.92 & $2.04^{\star}$ & 18.63 & 20.71 \\
\hline Jenkins Jumbo (1980) & 1.58 & 7.59 & $1.93^{\star \star}$ & 13.47 & 22.15 \\
\hline $77-2115$ & 1.00 & 7.60 & $1.10^{*}$ & 14.54 & 10.00 \\
\hline $77-1765$ & 0.38 & 6.32 & $0.45^{\star \star}$ & 15.78 & 18.42 \\
\hline
\end{tabular}

1) Number in parenthesis refers to year in which the line was grown.

* Significantly different from the corresponding Mean SWE at the $5 \%$ level.

** Significantly different from the corresponding Mean SWE at the $1 \%$ level. 
Table 16. Mean and coefficient of variation (CV) for SWE and corresponding ABOSW per generation for the cross and reciprocal cross populations and the percentage weight increase due to abortion.

\begin{tabular}{|c|c|c|c|c|c|}
\hline $\begin{array}{c}\text { Generation } \\
\text { and } \\
\text { Cross }\end{array}$ & $\begin{array}{l}\text { Mean } \\
\text { SWE }\end{array}$ & $\mathrm{CV}$ & $\begin{array}{l}\text { Mean } \\
\text { ABOSW }\end{array}$ & $\mathrm{CV}$ & $\begin{array}{c}\% \\
\text { Weight } \\
\text { Increase }\end{array}$ \\
\hline \multicolumn{6}{|c|}{$\mathrm{F}_{2}$ Generation } \\
\hline $594 \mathrm{~A}$ & 0.51 & 17.84 & $0.63^{\star \star}$ & 22.22 & 23.53 \\
\hline $594 B$ & 0.49 & 19.39 & $0.59 \star \star$ & 23.73 & 20.41 \\
\hline $595 A$ & 0.46 & 14.13 & $0.59 \star \star$ & 23.73 & 28.26 \\
\hline $595 B$ & 0.46 & 10.00 & $0.53^{\star \star}$ & 18.87 & 15.22 \\
\hline $596 A$ & 0.63 & 17.46 & $0.80 \star \star$ & 16.25 & 26.98 \\
\hline $696 B$ & 0.63 & 17.46 & $0.79 * \star$ & 21.52 & 25.40 \\
\hline $597 A$ & 0.53 & 18.68 & $0.64 \star \star$ & 20.31 & 20.75 \\
\hline $597 \mathrm{~B}$ & 0.55 & 21.82 & $0.68 * \star$ & 22.06 & 23.64 \\
\hline \multicolumn{6}{|c|}{$\mathrm{F}_{3}$ Generation } \\
\hline $594 \mathrm{~A}$ & 0.49 & 17.75 & $0.53^{*}$ & 22.64 & 8.16 \\
\hline 5948 & 0.45 & 24.44 & $0.52^{\star \star}$ & 25.00 & 15.56 \\
\hline $596 \mathrm{~A}$ & 0.66 & 22.73 & $0.81^{\star \star}$ & 24.69 & 22.73 \\
\hline $596 \mathrm{~B}$ & 0.60 & 21.67 & $0.78^{\star \star}$ & 21.79 & 30.00 \\
\hline
\end{tabular}

* Significantly different from the corresponding Mean SWE at the $5 \%$ level.

**Significantly different from the corresponding Mean SWE at the $1 \%$ level. 
It can be noted in Table 15 that the parental lines differed in the extent to which seed weight was increased due to abortion. Percentages ranged approximately from 7 for Early Bunch in 1979 to 22 for Jenkins Jumbo in 1980. Perhaps the most important fact is that Early Bunch and 77-2115 were the lines that presented the lowest percentage weight increase. Early Bunch is a highly improved line. Its seeds fill the pod well but are not so tightly packed to the point of causing excessive seed damage during shelling operations. Line 77-2115 has a background common to Early Bunch and is described as a line whose pods are not well-filled.

The above observations are evidence that, although the size of the pod cavity may influence, by mechanical restraint, the final size of seeds, seeds with genotypes for a size smaller than the space provided by the pod may stop growing before the pod is fully filled. Lines Krinkle, Jenkins Jumbo and 77-1765 generally fill their pods well. The percentage weight increase due to abortion in these three genotypes ranged from 18 for line 77-1765 to 22 for Jenkins Jumbo in 1980.

The ABOSW in segregating populations from crosses involving the mentioned parents can be observed in Table 16 compared to the respective SWE. Means of ABOSW were significantly different from the SWE means at the $1 \%$ level, except for Cross $594 \mathrm{~A}$ in the $\mathrm{F}_{3}$ generation, where the means were different at the $5 \%$ level.

Although the differences in percentage weight increase between the segregating populations were not so clearcut, some observations can be made. Except for the Cross 594, the other three crosses had either 
Early Bunch or 77-2115 as one of the parents. In fact, considering both the cross and reciprocal together for each cross, it can be noted that Cross 596 produced percentage weight increases higher than the other three crosses. These observations demonstrate that there are differences between genotypes in their potential ability to produce larger seeds, irrespective of the size of the pod cavity. In addition, it must be pointed out that the final size of seeds when born in two-seeded pods does not appear to be an indicator of how large the seeds can grow when given more space. Early Bunch seeds are larger than Krinkle seeds and seem to have less ability to grow further. However, Jenkins Jumbo seeds are larger than Early Bunch and still, remarkably, show a higher percentage weight increase due to abortion. Despite the fact that Jenkins Jumbo seeds average over 1.5 grams in "normal pods", they reached 2.0 grams/seed in "aborted" pods.

\section{Growth of Individual Parental and $F_{7}$ Seeds}

Dure (1975) provided a generalized description of the developmental pattern of legume seed formation, characterizing three phases: one exponential (rapid cell division and size increase), one linear (growth at a steady rate) and one (plateau) corresponding to cessation of growth and dessiccation.

Comparisons between the growth of Krinkle and Jenkins Jumbo seeds and of the $F_{1}$ seeds resulting from reciprocal crosses between them are shown in Figure 7. Regression lines were fitted to the data points so as to better identify the distinct phases in each of the four genotypes, especially the linear phase (Table 17). 


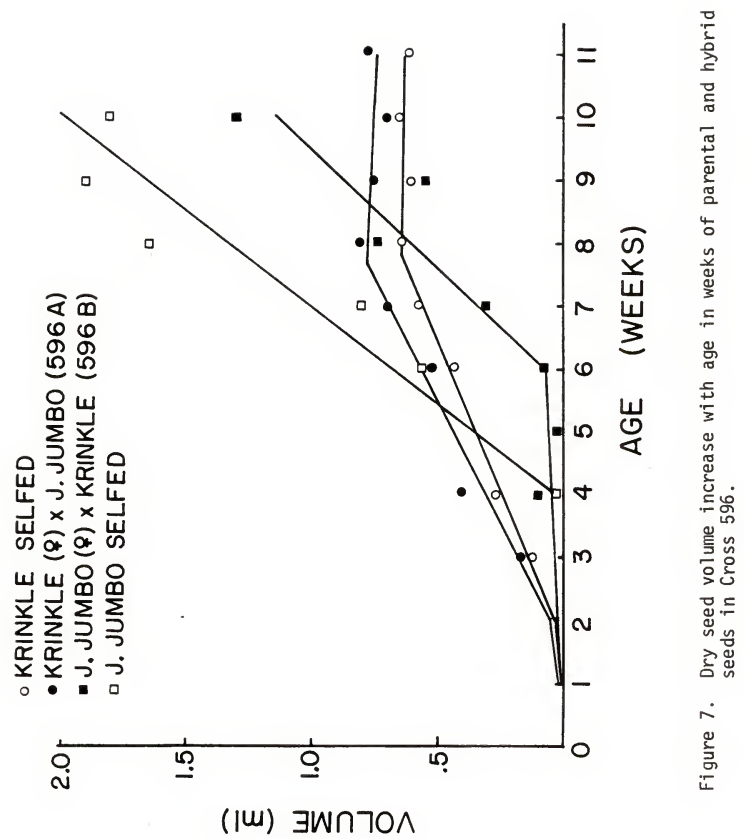


Table 17. Regression equations and coefficients of determination $\left(r^{2}\right)$ for dry seed volume and weight $(Y)$ against fruit age in weeks $(x)$ during the linear phase in parental and reciprocal hybrid seeds of Cross 596 .

\begin{tabular}{|c|c|c|c|}
\hline \multirow{2}{*}{$\begin{array}{l}\text { Parent } \\
\text { or } \\
\text { hybrid }\end{array}$} & \multirow{2}{*}{$\begin{array}{l}\text { Linear } \\
\text { phase } \\
\text { (weeks) }\end{array}$} & \multicolumn{2}{|c|}{ Equation $\left(r^{2}\right)$} \\
\hline & & Volume & Weight \\
\hline Krinkle & $2-8$ & $\begin{array}{c}Y=-0.19+0.11 x \\
\left(r^{2}=0.98\right)\end{array}$ & $\begin{aligned} Y= & -0.20+0.10 x \\
& \left(r^{2}=0.99\right)\end{aligned}$ \\
\hline $596 \mathrm{~A}$ & $2-8$ & $\begin{aligned} Y=-0.22+0.13 x \\
\\
\left(r^{2}=0.97\right)\end{aligned}$ & $\begin{aligned} Y= & -0.17+0.12 x \\
& \left(r^{2}=0.92\right)\end{aligned}$ \\
\hline $596 \mathrm{~B}$ & $6-10$ & $\begin{array}{c}Y=-1.56+0.27 x \\
\left(r^{2}=0.83\right)\end{array}$ & $\begin{array}{c}Y=-1.45+0.25 x \\
\left(r^{2}=0.79\right)\end{array}$ \\
\hline J. Jumbo & $4-10$ & $\begin{array}{c}Y=-1.44+0.35 x \\
\left(r^{2}=0.92\right)\end{array}$ & $\begin{array}{c}Y=-1.36+0.32 x \\
\left(r^{2}=0.94\right)\end{array}$ \\
\hline
\end{tabular}


The first phase could not be readily identified since a much larger number of observations should be concentrated in that region in order to quantify it. However, it could be observed that this initial phase is rather short in krinkle seeds (around two weeks), while in Jenkins Jumbo seeds this phase appeared to be longer, lagging behind that of Krinkel by two weeks, i.e., the linear phase started four weeks after pegging. Schenk (1961) reported three weeks' lapse before the beginning of the linear phase in Virginia-type seeds.

Significant observations can be made regarding comparison between the linear phases. Large differences could be observed between the two parents, linear growth of Krinkle seeds proceeding at a much lower rate than that of Jenkins Jumbo. Growth (in dry volume) of Krinkle seeds, calculated from Weeks 2 to 8 , was approximately $0.015 \mathrm{ml}$ per day, corresponding to a dry weight increase of $15 \mathrm{mg} / \mathrm{seed} /$ day. For Jenkins Jumbo, the daily increase in volume, as calculated from weeks four to ten, was 0.047 which was approximately $46 \mathrm{mg} / \mathrm{seed} /$ day as obtained from the dry weight measurements.

The end of the linear phase could be observed in Krinkle. Seeds increased steadily in size until week 8 , after which no more growth was observed. At Week 10, when the last sampling was taken for Jenkins Jumbo, seeds were still growing linearly and the growth rate showed no signs of levelling off. Since at this point seeds had not reached the final size characteristic of the variety, it is assumed that the linear phase was to continue for a certain time beyond the tenth week, making this period longer than forty-two days. 
The similarity in the shape of the curves obtained from the hybrid seeds in relation to their female parents is readily noticeable, showing the effect of the maternal genotype on seed size. However, the hybrid seeds in Krinkle pods grew at a little faster rate than the selfed seed of Krinkle, reaching a larger size by the eighth week. At that point the difference between these two means was significant at the $5 \%$ leve1. The rate of growth of $596 \mathrm{~A}$ seeds, as measured during the linear phase, was calculated as 0.018 mililiters of increase in volume per day, which corresponds to $18 \mathrm{mg} / \mathrm{seed} /$ day on a dry weight basis.

Comparisons between fresh and dry measurements of volume can be helpful in explaining the degree of expansion of the embryonic tissue and the extent to which it reduces in size upon drying. Figure 8 shows the growth of 596A and Krinkle seeds measured as fresh volume of two seeds. Here, the differences in growth rate between parental and hybrid seeds are even more apparent. Krinkle seeds appeared to have reached their maximum size by week seven while the hybrid seeds reached their maximum as early as the fourth week. The near-horizontality of the line from week four to week eleven suggests that the hybrid seeds were considerably restrained by the pod wall after week four. It can be seen that, at that time, krinkle pods had already reached their maximum sizes (Figure 9).

It can be suggested that, due to this rapid expansion early in fruit development, the swollen hybrid seeds may exert a strong pressure against the pod wall to the point of enlarging the pod. In fact, it could be noticed that the hybrid 596A seeds were indeed a little larger than would be expected. The volume of two dry Krinkle seeds from the same plants averaged $0.62 \mathrm{ml}$, which is close to that obtained in field 


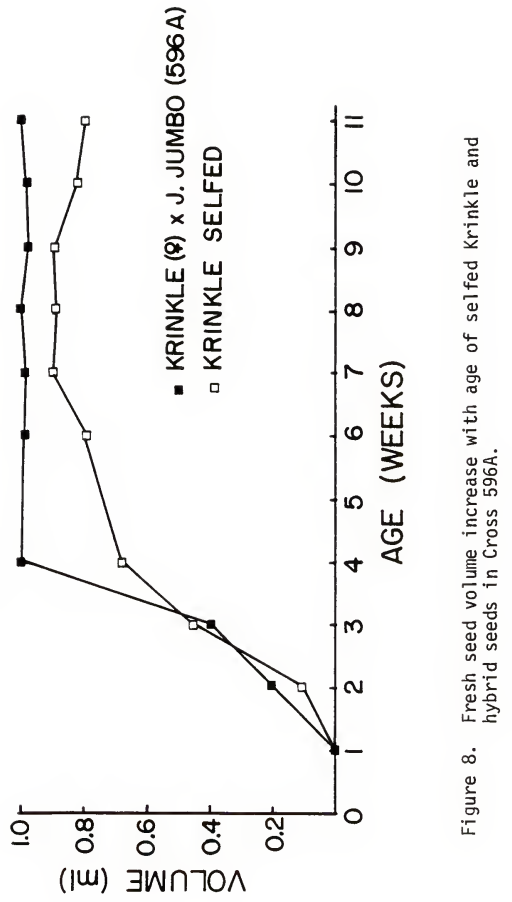




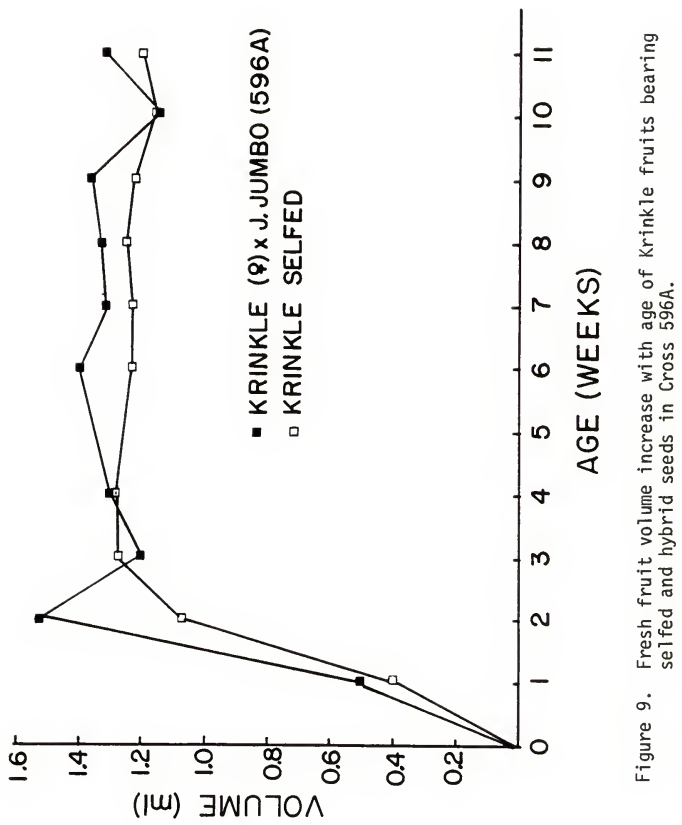




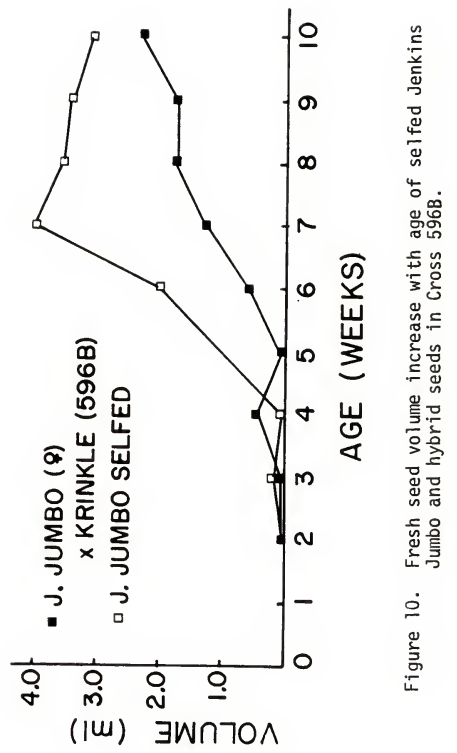




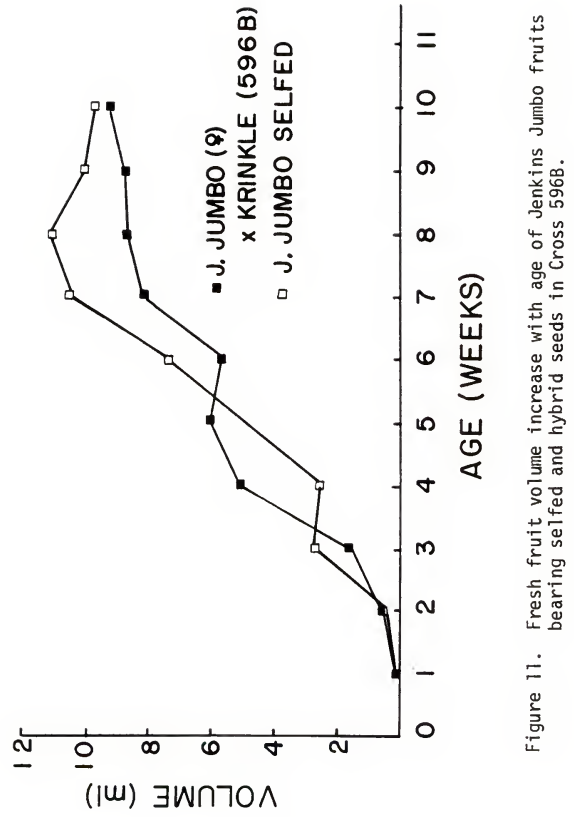


conditions $(0.60 \mathrm{ml})$, while the mean volume for $596 \mathrm{~A}$ seeds at week eleven was $0.78 \mathrm{ml}$. In addition, as shown in Figure 9, the pods bearing the hybrid seeds were also slightly larger (1.32 $\mathrm{ml}$ of fresh volume) than those bearing the parental seeds $(1.20 \mathrm{ml})$.

In previous crosses, using either Krinkle or Jenkins Jumbo as one of the parents, it was observed that the $F_{1}$ seeds growing within the small parental pods were slightly heavier than the selfed counterparts. The difference was attributed to the fact that the parental seeds were somewhat undersized due to being originated from later flowers (Godoy and Norden, 1981). However, in the present case, this cause was eliminated by crossing and self-pollinating during the same period of time.

It is difficult to make conclusive statements, since the samples used in each data point were small and, also, because only one cross with two genotypes was evaluated. However, the observations suggest that not only can the growth of the $F_{1}$ seeds can be restrained by the pod cavity but also that, due to the larger genotype, these seeds can exert some pressure against the pod wall causing some extra enlargement of the pod.

A few cases are reported in the literature which provide some further evidence for the above. Smith (1950) had stated that "the shapes and orientations of the seeds determine the forms of pod segments and the depths of the constrictions." Davies (1975) observed the appearance of $F_{1}$ seeds larger than both parental seeds in pea crosses. In common beans, a plant which produces very small pods produced pods up to twice as large when crossed with pollen from a large-podded line. The phenomenon was described as "metaxenia" and it was suggested that 
the effect would be caused by hormones produced by the embryo, especially during the first 5-10 days of pod growth (Freytag, 1979).

Hybrid 596B seeds presented a growth pattern more similar to Jenkins Jumbo seeds. However, some differences could be noticed between the two curves in Figure 7 resulting in smaller $F_{1}$ seeds at the end of the tenth week. The most marked difference appeared to occur at the initial phase, before the seeds resumed linear growth. This phase was two weeks longer in the hybrid than it was in the parental seeds. The linear phase, represented by the line judged to best $f$ it the data for dry seeds, appeared to start on week 6 and to cont inue beyond week 10 . The growth rate modification due to the cross also appears evident in the fresh seeds (Figure 10). While 596B hybrid seeds were still increasing in size by week 10 , the selfed Jenkins Jumbo seeds appeared to have reached their maximum fresh volume at week 7 , the point at which the fresh seeds may have started reaching the pod wall (Figure 11).

The difference in rate of linear growth between 596B hybrid and Jenkins Jumbo seeds can be observed in Figure 7. Measured from weeks 6 to 10 , the calculated rate of volume increase for $596 \mathrm{~B}$ seeds was 0.038 mililiters per day, which is equivalent to $36 \mathrm{mg} / \mathrm{seed} /$ day when calculated from the curves of dry weight. As mentioned before, the growth rate of Jenkins Jumbo seeds was $46 \mathrm{mg} / \mathrm{seed} /$ day on a dry weight basis. Additional data would be necessary to provide more precise information on the effect of the seed's genotype on its final size. However, results from a wide cross such as between Krinkle and Jenkins Jumbo provide an indication that both maternal and embryonic genotypes contribute to the size expression of the seeds, although the type and extent of the 
influence that the maternal environment has on the growth of hybrid seeds cannot be established with certainty.

Since $596 \mathrm{~B}$ seeds grew within a larger pod cavity, it would be expected that the growth pattern would be one more closely resembling an average between the parents. As this was not the case, a maternal influence can be suggested, probably related to the supply of assimilates from the mother-plant to the seeds. On the other hand, it can also be suggested that this influence is not total, since growth of $596 \mathrm{~B}$ and Jenkins Jumbo seeds were evidently dissimilar. Regarding this dissimilarity, it appears that some event occurring prior to the linear phase, probably related to cotyledonary cell division (Dure, 1975), is the most important effect accounting for some difference in seed size between these hybrids and the large parental seeds at the end of week 10. 
The objective of this research was to examine the genetics and interrelationships of fruit and seed size on the basis of their differential segregation, in crosses involving peanut genotypes widely different in these traits.

Four crosses were made involving small and large-podded peanut genotypes and average fruit and seed dry weight and volume were recorded as size parameters. Generations $F_{1}$ and $F_{2}$ were evaluated for the four crosses and two of them were increased to $F_{3}$. Average dry weight of seeds and shells in all generations were compared and frequency distributions were plotted. Estimates of broad-sense heritability and genotypic correlations were calculated for size traits and other characteristics. Narrow-sense heritabilities were calculated in two of the crosses by regression of $F_{3}$ progeny means on $F_{2}$ plants and of $F_{3}$ individual plants on individual $F_{2}$ fruits and seeds. In the cross between Krinkle $x$ Jenkins Jumbo, the growth of individual parental and hybrid seeds was measured on a weekly basis to assess the influence of the seed's genotype on fruit and seed size.

Crossing genotypes widely different in pod and seed size produced significant deviations of the offspring means toward the small parent. Thus it would be difficult to recover large podded types among segregates of such crosses. However, since only a few $F_{1}$ plants were 
used to produce the $F_{2}$ generation, it is possible that the distribution of the $F_{2}$ can be broadened to a certain extent, by working with a larger number of $F_{7}$ 's.

The present results agree with the hypothes is that size traits are actually governed by genes that modify growth rates (or rates of cell division) since the offspring means agree better with the geometric rather than with the arithmetic mean of the peanuts. Thus, dominance effects should be tested against the geometric mean. The tests of dominance indicated that there may be dominance present in some of the crosses, especially in Cross 597. However, the effect was much less noticeable in the geometric scale. The lack of strong dominance is also confirmed by the small differences observed between narrow and broad sense heritabilities for size traits. In addition to the multiplicative effects and the presence of some dominance even when the geometric means were used, there was a further reduction of $F_{2}$ and $F_{3}$ means. However, the hypothesis of inbreeding depression cannot explain this reduction, since inbreeding depression caused by the presence of dominance would place the $F_{2}$ and $F_{3}$ means between the $F_{1}$ and the midparent.

The high correlations between fruit and seed size in segregating populations, also shown by the similarity between the distributions of seed and shell weight, indicate that there is a large influence of the maternal environment on the expression of seed size. This can also be confirmed by the similarity in growth rate of reciprocal $F_{1}$ seeds with their selfed counterparts. However, evidence was provided that the seed's own genotype also plays a role in its final phenotypic expression: 1) The genotype of the hybrid $F_{1}$ seeds in the cross Jenkins 
Jumbo, as the female, with Krinkle pollen produced a modification in their growth pattern in relation to that observed in selfed Jenkins Jumbo seeds; 2) Seeds grown within pods in which one seed had aborted appeared to continue growing, the extent of the additional growth differing among genotypes; and 3) Although seed size follows a pattern of segregation similar to that of pod size (reason for the high correlations existing between both traits) there still is variation in the ability of the seeds to fill the pods completely, seeds being generally more tightly packed in the smaller pods.

These results indicate that the maternal influence of the pod size on seed is partial because the segregates varied in the extent to which the pods are filled by the seeds. Indications are that this characteristic can be genetically manipulated since narrow-sense heritabilities for traits such as fruit density and shelling percentage were found to be around 0.50 .

The results obtained also demonstrate that the cavity provided by the pods, in which seeds will develop, may be an important cause for yield reduction since seeds are not always able to grow to their full potential. This could be observed by the larger size attained by some seeds when growing under reduced pod restraint. In addition, hybrid seeds from Cross 596 when growing in Krinkle pods clearly showed the limitation of the pod size to seed growth. This is important in peanuts because although there may be some stretching of the pod tissue, it is probably not significant, since peanut pods turn into rigid structures as they approach maturity. 
The significant and negative correlation estimates between number of pods and size traits obtained, especially in Cross 596 ( $r=-0.34 \star \star$ to $-0.74 \star \star$ ) suggest that detectable relationships between these traits were conditioned by substantial differences in size among the segregates. Percentage of mature pods was not significantly correlated with size or pod-filling traits in most populations. Correlations ranged from $r=0.00$ to $0.36^{\star \star}$. The percentage of fruits with aborted seeds also failed to show a consistently strong relationship with either fruit or seed size $\left(r=-0.08\right.$ to $\left.+0.28^{\star *}\right)$. The correlations between the percentage of fruits with aborted seeds and the percentage of mature fruits tended to be negative $\left(r=-0.02\right.$ to $\left.-0.61^{\star \star}\right)$.

Except for Cross $597 \mathrm{~B}$ where shell weight was significantly and negatively correlated with the percentage of split pods $\left(r=00.41^{\star *}\right)$, the size traits did not show a consistent relationship of pod splitting since the estimates ranged from $r=-0.17$ to +0.22 . Pod splitting was also not consistently associated with fruit density $(r=-0.12$ to $\left.+0.26^{\star}\right)$.

The results could not strongly indicate that the amount of seed abortion and pod splitting was a result of the growth of genetically larger seeds in small pods. However, the broad-sense heritabilities for the percentage of pods with aborted seeds $\left(H^{2}=0.74\right.$ to 0.90$)$ and for the percentage of $\mathrm{split}$ pods $\left(\mathrm{H}^{2}=0.59\right.$ to 0.94$)$ suggest that a substantial portion of the variation among the segregates was due to genet ic causes.

The lower narrow-sense heritabilities estimated by the regression of $F_{3}$ plants on $F_{2}$ individual fruits and seeds $\left(h^{2}=0.44\right.$ to 0.66$)$ in contrast to the regression of $F_{3}$ lines on $F_{2}$ plants $\left(h^{2}=0.72\right.$ 
to 0.83 ) indicate that selection of fruit or seed size on a single fruit or seed basis would not be as efficient as on a plant basis.

The calculated minimum number of factors for seed and shell weight ranged from 4 to 26 suggesting that such traits should be treated quant itatively. 


\section{BIBL IOGRAPHY}

Asana, R.D., and A.K. Bagga. 1966. Studies in physiological analys is of yield. VIII. Comparison of development of upper and basal grains of spikelets of two varieties of wheat. Ind. J. Plant Physiol. $9: 1-21$.

Asana, R.D., and R.F. Williams. 1965. The effect of temperature stress on grain development in wheat. Aust. J. Agri. Res. 16:1-13.

Bailey, W.K., and J.E. Bear. 1973. Components of earliness of maturity in peanuts, Arachis hypogaea L. Journ. Am. Peanut Res. \& Educ. Assoc. 5(1): $\overline{32-39}$.

Bassett, M.J., and F.E. Woods. 1978. A procedure for combining a quantitative inheritance study with the first cycle of a breeding program. Euphytica 27:295-303.

Bhatt, G.M. 1972. Inheritance of heating date, plant height, and kernel weight in two spring wheat crosses. Crop Sci. 12:95-98.

Bingham, J. 1967. Investigations on the physiology of yield in winter wheat, by comparisons of varieties and by artificial variation in grain number per ear. J. Agric. Sci. 68:411-422.

Brim, C.A., W.M. Shutz, and F.I. Collins. 1968. Maternal effect on fatty acid composition and oil content of soybeans, Glycine max L.). Merril. Crop Sci. 8:517-518.

Brocklehurst, P.A. 1977. Factors controlling grain weight in wheat. Nature (London) 6:348-349.

Cahaner, A.J. Hillel, and A. Ashri. 1979. Detection of genic interactions by anlyzing the $F_{2}$ generation of diallel crosses. Theor. App 1. Genet. 55:161-167.

Carter, M.W., and C.G. Poneleit. 1973. Black layer maturity and filling period variation among inbred lines of corn (Zea mays L.). Crop Sci. 13:436-439.

Coffelt, T.A., and R.0. Hammons, 1974. Correlations and heritability studies of $n$ ine characters in parental and infraspecific-cross populations of Arachis hypogaea. Oleagineux 22(1):23-27.

Davies, D.R. 1975. Studies of seed development in Pisum sativum. I. Seed Size in reciprocal crosses. Planta (Ber1.) $124: 297-302$.

Davies, D.R. 1977. DNA contents and cell number in relation to seed size in the genus Vicia. Heredity $39(1): 153-163$. 
Daynard, T.B., J.W. Tanner and W.G. Duncan. 1971. Duration of the grain filling period and its relation to grain yield in corn Zea mays L. Crop Sci. 11:45-48.

Dickson, M.H. 1967. Diallel analys is of seven economic characters in snap beans. Crop Sci. 7:121-124.

Dixit, P.K., P.D. Bhargava, D.K. Saxena, and L.K. Bhatia. 1970. Estimates of genotypic variability of some quantitative characters in groundnut (Arachis hypogaea L.). Indian J. Agric. Sci. $40(3): 197-202$.

Dixit P.K., P.D. Bhargava, D.K. Saxena, L.K. Bhatia and K.N. Sharma. 1971. Variability in groundnut (Arachis hypogaea L.). Indian J. Agric. Sci. $41(8): 685-691$.

Duncan, W.G., D.B. Egli, and D.E. McCloud. 1979. The determination of seed number and filling period duration in peanuts, soybeans and maize. Unpublished.

Dunstone, R.L., and L.T. Evans. 1974. Role of changes in cell size in the evolution of wheat. Aust. J. Plant Physiol. 1:157-165.

Dure, L.S. 1975. Seed formation. Ann. Rev. Plant Physiology 26:259278.

Egli, D.B., and J.E. Leggett. 1976. Rate of dry matter accumulation in soybean seeds with varying source-sink ratios. Agron. J. 68:371374.

Egli, D.B. 1975. Rate of accumulation of dry weight in seeds of soybeans and its relationship to yield. Can. J. Plant Sci. 55:215-219.

Falconer, D.S. 1976. Introduction to quantitative genetics. The Ronald Press Company, New York. Eighth Printing. 365 pp.

Egli, D.B., J.E. Leggett, and J.M. Wood. 1978. Influence of soybean seed size and position on the rate and duration of filling. Agronomy Jour. 70:127-130.

Freytag, G.F. 1979. Metaxenia effects on pod size development in the common bean. The Journal of Heredity. 70:444-446.

Garwood, D.L., and R.J. Lambert. 1967. Protein differences in reciprocal crosses. Maize Genetics Cooperation News letter 41:65.

Garwood, D.L., E.J. Weber, R.J. Lambert and D.E. Alexander. 1970. Effect of different cytoplasms on oil, fatty acids, plant height and ear height of maize (Zea mays L.). Crop Sci. 10:39-41.

Gibori, A., J. Hillel, A. Cahaner, and A. Ashri. 1978. A 9x9 diallel analys is in peanuts (A. hypogaea L.): Flowering time, tops' weight, pod yield per plant and pod weight. Theor. Appl. Genet. 53:169-179. 
Godoy, I.J., and A.J. Norden. 1981. Shell and seed size relationships in peanuts. Peanut Science $8: 21-24$.

Grami, B., and B.R. Stefansson. 1977. Paternal and maternal effects on protein and oil content in summer rape. Can J. Plt. Sci. 57:945949 .

Gregory, W.C., B.W. Smith, and J.A. Yarbrough. 1951. In The Peanut-The Unpredictable Legume. pp. 28-88. Nat. Fert. As $\overline{\mathrm{SO}}$. ., Washington, D.C.

Halliburton, B.W., W.G. Glasser, and J.M. Byrne. 1975. An anatomical study of the pericarp of Arachis hypogaea, with special emphas is on the sclereid component. Bot. Gaz. 136(2):219-223.

Hammons, R.D. 1964. Krinkle, a dominant leaf marker in the peanut, Arachis hypogaea L. Crop Sci. 4(1):22-24.

Hammons, R.0. 1973. Genetics of Arachis hypogaea. Chap. 4, pp. 135173. In: Peanuts--Culture and Uses. Amer. Peanut Res. and Educ. Assoc. Inc., Stillwater, Okla.

Hammons, R.0., and A.J. Norden. 1979. Registration of Jenkins Jumbo peanut. Crop Sci. 19:132.

Hayes, T.R. 1933. The classification of groundnut varieties with a preliminary note on the inheritance of some characters. Trop. Agric. (West Indies) 19:318-327.

Hedley, C.L., and J.J. Ambrose. 1980. An analys is of seed development in Pisum sativum. L. Ann. Bot. 46:89-105.

Hsu, F.C. 1979. A developmental analys is of seed size in common bean. Crop Sci. 19:226-230.

Hull, F.H. 1937. Inheritance of rest period of seeds and certain other characteristics in the peanut. Fla. Agric. Expt. Sta. Tech. Bu11. 314. 46 pages.

Jenner, C.F., and A.J. Rathjen. 1978. Physiological basis of genetic differences in the growth of grains of six varieties of wheat. Aust. Jour. Plt. Physiol. 5:249-262.

- Kilen, T.C. 1980. Paternal influence on $F_{1}$ seed size in soybean. Crop Sci. 20:261-262.

Koller, H.R. 1971. Analysis of growth within distinct stracta of the soybean community. Crop Sci. 11:400-402.

Kotecha, A., and L.H. Zimmerman. 1978. Inheritance of seed weight, pappus, and striped hull in safflower species. Crop Sci. 18:999-1003.

Kushwaha, J.S., and M.L. Tawar. 1973. Estimates of genotypic and phenotypic variability in groundnut (Arachis hypogaea L.). Indian J. Agric. Sci. 43(12): 1049-1054. 
Leleji, 0.K., M.H. Dickson, L.V. Crowder, and J.B. Bourke. 1972. Inheritance of crude protein percentage and its correlation with weed yield in beans, Phaseolus vulgaris L. Crop Sci. 12:168-171.

MacArthur, J.W., and L. Butler. 1938. Size inheritance and geometric growth processes in the tomato fruit. Genetics 23:253-268.

Mahmud, I., and H.H. Kramer. 1951. Segregation for yield, height, and maturity following a soybean cross. Agron. Jour. 43:605-609.

Mak, C., and T.C. Yap. 1980. Inheritance of seed protein content and other agronomic characters in long bean (Vigna sesquipedal is Fruw.) Theor. Appl. Genet. 56:233-239.

Martin, J.P. 1967. Contribution a l'etude de certains caracteres d'importance agronomique chex l'arachide. Edute de l'heredite de la richesse enhuile, du rendement au decorticage et de la grosseur des graines dans le groupe des varietes tardives. (French). (Oleagineux 22(11):673-676). (French; English summary).

Millet, E., and M.J. Pinthus. 1980. Genotypic effects of the maternal tissues of wheat on its grain weight. Theor. Appl. Genet. 58:247252.

Milthorpe, F.L., and J. Moorby. 1974. An Introduction to Crop Physiology. Cambridge University Press. 202 pp.

Mohammed, J., J.C. Wynne, and J.0. Rawlings. 1978. Early generation variability and heritability estimates in crosses of Virginia and Spanish peanuts. 0leagineux $33(2): 81-86$.

Norden, A.J. 1973. Breeding of the cultivated peanut. Chap. 5, pp. 175-208. In: Peanuts--Culture and Uses. Amer. Peanut Res. and Educ. Assoc., Inc., Stillwater, Okla.

Norden, A.J., R.0. Hammons, and D.W. Gorbet. 1977. Performance of the Early Bunch (UF 70115) peanut variety. Agronomy Res. Rep. AG 77-8.

Openshaw, S.J., and H.H. Hadley. 1978. Maternal effects on sugar content in soybean seeds. Crop Sci. 18:581-584.

Patil, S.H. 1972. Induced mutations for improving quantitative characters of groundnut. Indian J. Genet. Plant Breed. 32(3):451458 .

Pawlowski, S.H. 1963. Methods for rapid determination of specific gravity of single seeds and seed samples and the correlation of specific gravity with oil content. Canadian Jour. Plant Sci. 43:150-156.

Pawlowski, S.H. 1964. Seed genotype and oil percentage relationship between seeds of a sunflower. Can. J. Genet. Cytol. 6:293-297.

Petr, F.C., and K.J. Frey. 1966. Genotypic correlations, dominance, and heritability of quantitative characters in oats. Crop Sci. $6: 259-262$. 
Porter, W.M. 1972. Genetic control of protein and sulfur contents in dry beans. Phaseolus vulgaris. Diss. Abstr. 33:4080B.

Quebedeaux, B., and R. Chollet. 1975. Growth and development of soybean (Giycine max (L.) Mer.) pods. Plant Physiol. 55:745-748.

Ramanathan, T., and V.S. Raman. 1968. Studies on the relation of certain genetic characters in hybrid populations of groundnut (Arach is hypogaea). J. Indian Bot. Soc. 45(1-2):113-116.

Sandhu, B.S., and A.S. Khehra. 1977. Genetic analys is of shelling percentage in groundnut. Indian J. Agric. Sci. 47(5):229-231.

Schenk, R.U. 1961. Development of the peanut fruit. Ga. Agr. Exp. Sta. Techn. Bul1. N.S. 22.

Singh, S.P. 1973. Heterosis and combining ability estimates in Indian mustard, Brassica Juncea L. Czern and Coss. Crop Sci. 13:497-499.

Singh, L., and H.H. Hadley. 1968. Maternal control of oil synthes is in soybeans, glycine max. (L.) Merril. Crop Sci. 8:622-625.

Singh, L., and H.H. Hadley. 1972. Maternal and cytoplasmic effects on seed protein content in soybeans. Glycine max. (L.). Merril. Crop Sci. 12:583-585.

Smith, B.W. 1950. Arachis hypogaea. Aerial flower and subterranean fruit. Amer. Jour. Bot. 37:802-815.

Smith, B.W. 1954. Reproductive efficiency in Arachis. Amer. Jour. Bot. $41: 607-616$.

Smith, B.W. 1956. Arachis hypogaea. Normal megasporogenes is and syngamy with occasional single fertilization. Amer. Jour. Bot 43:81-89.

Soomro, B. 1975. Inheritance of pod size, shell thickness and seed maturity in peanuts, Arach is hypogaea L.. Ph.D. thes is, Oklahoma State University, 64 pp.

Stamp, P.H., and G. Geisler. 1976. Der Verlauf des Kornwachstums in Abhangigkeit on der Kornsposition bei zivei Sommerweizensorten. $Z$. Acker Pflanzenbau. 142:264-274. (Cite from Jenner and Rathjen, 1978).

Steel, R.G.D., and J.H. Torrie. 1960. Principles and procedures of statistics. McGraw-Hill Book Company, Inc.

Sturkie, D.G., and G.A. Buchanan. 1973. Cultural practices. Chap. 9, pp. 299-313. In: Peanuts--Culture and Uses. Amer. Peanut Res. and Educ. Assoc., Inc., Stillwater, Okla.

Sun, P.L.F., H.L. Shands, and R.A. Forsberg. 1972. Inheritance of kernel weight in six spring wheat crosses. Crop Sci. 12:1-5. 
Syme, J.R. 1967 Growth and yield of irrigated wheat varieties at several rates of nitrogen fertilizer. Aust. J. Expt. Agric. Anim. Husb. 7:337-341.

Thomas, P.M., and Z.P. Kondra. 1973. Maternal effects on the oleic, linoleic and linolenic acid content of rapeseed oil. Can. J. Plant Sci. 53:221-225.

Thorne, J.H. 1979. Assimilate redistribution from soybean pod walls during seed development. Agronomy Jour. 71:812-816.

Weber, C.R. 1950. Inheritance and interrelation of some agronomic and chemical characters in an interspecific cross in soybeans (Glycine $\max \times$ G. ussuriensis. Iowa Agr. Exp. Sta. Res. Bu1. 374:765-816.

Weber, C.R., and B.R. Moorthy. 1952. Heritable and nonheritale relationships and variability of oil content and agronomic characters in the $F_{2}$ generation of soybean crosses. Agron. Jour. 44:202-209.

Williams, J.H., and J.C.S. Allison. 1978. Genetic differences in the growth of groundnut (Arachis hypogaea L.) pods and kernels. Rhod. J. Agric. Res. 16:73-77.

Wynne, J.C., D.A. Emery and P.W. Rice. 1970. Combining ability estimates in Arachis hypogaea L. II. Field performance of $F_{1}$ hybrids. Crop. Sci. 19:713-715.

Wynne, J.C. and J.0. Rawlings. 1978. Genetic variability and heritability for an intercultivar cross of peanuts. Peanut Science 5:23-26.

Yermanos, D.M., S. Hemstreet, and J.J. Garber. 1967. Inheritance of quality and quantity of seed oil in sunflower (Carthamus tinctorius L.) Crop Sci. 7:417-422.

Ziv, M., and E. Zamski. 1975. Geotropic responses and pod development in gynophore explants of peanut (Arachis hypogaea L.) culture "in vitro". Ann. Bot. 39:579-583.

Ziv, M., and E. Zamski. 1976. Pod formation and its geotropic orientation in the peanut, Arachis hypogaea L., in relation to light and mechanical stimulus. Ann. Bot. 49:631-636. 


\section{BIOGRAPHICAL SKETCH}

Ignacio J. de Godoy was born in Amparo (SP), Brasil, on June 30, 1948, to Ignacio and Isabel de Godoy.

He was reared in Campinas where he attended primary and secondary schools. In 1969, he enrolled at the University Julio de Mesquita (Botucatu - SP - Brasil) from where he took his B.S. in Agronomy in 1972.

After graduation, he worked in rural extension, planning and technical assistance for 3 years. In 1975, he joined the Instituto Agronomico de Campinas (SP - Brasil) to work on oilseed crops research. In March 1977 he entered the University of Florida, Agronomy Department, receiving his Master of Science degree in 1979. Since then, he has pursued his Ph.D. degree in Agronomy which he will receive in August 1981. He is currently a member of American Society of Agronomy, American Peanut Research and Education Society and the Gamma Sigma Delta honor society. 
I certify that I have read this study and that in my opinion it conforms to acceptable standards of scholarly presentation and is fully adequate, in scope and quality, as a dissertation for the degree of Doctor of Philosophy.

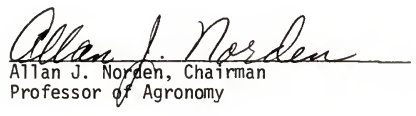

I certify that I have read this study and that in my opinion it conforms to acceptable standards of scholarlv presentation and is fully adequate, in scope and quality, as a dissertation for the degree of Doctor of Philosophy.

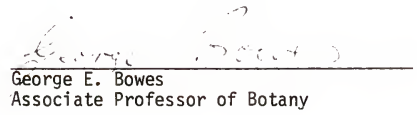

I certify that I have read this study and that in my opinion it conforms to acceptable standards of scholarly presentation and is fully adequate, in scope and quality, as a dissertation for the degree of Doctor of Philosophy.

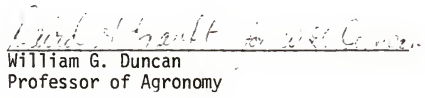

I certify that I have read this study and that in my opinion it conforms to acceptable standards of scholarly presentation and is fully adequate, in scope and quality, as a dissertation for the degree of Doctor of Philosophy. 
I certify that I have read this study and that in my opinion it conforms to acceptable standards of scholarly presentation and is

fully adequate, in scope and quality, as a dissertation for the degree of Doctor of Philosophy.

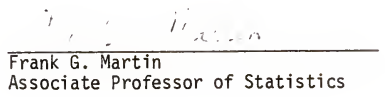

This dissertation was submitted to the Graduate Faculty of the College of Agriculture and to the Graduate Council, and was accepted as partial fulfillment of the requirements for the degree of Doctor of Philosophy.

August 1981

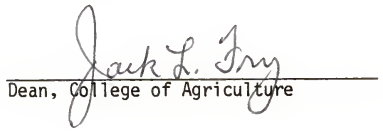

Dean for Graduate Studies and Research 